\title{
RETENÇÃO DA ÁGUA EM SOLO SOB DIFERENTES USO NO ECOSSISTEMA TABULEIROS COSTEIROS
}

\author{
JEANE CRUZ PORTELA \\ Engenheira Agrônoma
}

Orientador: Prof. Dr. Paulo Leonel Libardi

\begin{abstract}
Dissertação apresentada à Escola Superior de Agricultura "Luiz de Queiroz" da Universidade de São Paulo, para obtenção do título de Mestre em Agronomia, Área de concentração: Solos e Nutrição de Plantas.
\end{abstract}

P I R A C I C A B A

Estado de São Paulo - Brasil

Março - 2000 


\title{
Dados Internacionais de Catalogação na Publicação (CIP) DIVISÃO DE BIBLIOTECA E DOCUMENTAÇÃO - Campus "Luiz de Oueiroz"/USP
}

\author{
Portela, Jeane Cruz \\ Retenção da água em solo sob diferentes usos no ecossistema tabuleiros costeiros / \\ Jeane Cruz Portela. - - Piracicaba, 2000. \\ 53 p. \\ Dissertação (mestrado) - Escola Superior de Agricultura Luiz de Queiroz, 2000. \\ Bibliografia. \\ 1. Água do solo 2. Curva de retenção 3. Ecossistema agrícola 4. Latossolo 5. \\ Relação solo-água-planta 6. Tabuleiro costeiro I. Titulo
}

CDD 631.432

"Permitida a cópia total ou parcial deste documento, desde que citada a fonte -0 autor" 
Aos meus pais, Jacira e Alexandre Portela irmãos, Jaciara, Jacia, Marcelo, Jacy, Jamile e Jadie e sobrinhos, Lucas, Alexandre, Alisson e Mariana, pelo nosso amor.... 


\section{Agradecimentos}

À Deus, pelo dom da vida; permitindo-me alcançar mais um degrau.

Ao Prof. Dr. Paulo Leonel Libardi, pela paciência, carinho, compreensão, ensinamentos oferecidos e pelas sábias palavras, nos momentos em que mais precisei.

Ao conselho do Curso de Pós-graduação em Solos e Nutrição de Plantas da ESALQ/USP, pela oportunidade.

Ao Dr. Luciano da Silva Sousa e aos laboratoristas da EMBRAPACNPMF, Ariovaldo Conceição Santos e Roque Francisco Barbosa, pela valiosa colaboração na coleta das amostras.

Ao Prof. Dr. Sérgio Oliveira Moraes, pelo estímulo, confiança e por sempre estar disposto a colaborar.

Ao Prof. Dr. Quirijn de Jong van Lier, pela valiosa colaboração no tratamento matemático dos dados na execução deste trabalho.

Ao Prof. Dr. Cássio A. Tormena pelas sugestões.

Ao Prof. Dr. Álvaro Pires da Silva, pela concessão de uso do Laboratório de Física do Solo do Depto. de Ciências do Solo e Nutrição de Plantas, onde parte das análises foram realizadas.

Aos funcionários Luiz Fernando Novello e Francisco Bernardo Dias, pelo apoio em todas as etapas deste trabalho e aos demais funcionários, do Departamento de Ciências Exatas, Ana Maria Michelon, Robinson Tuon, Edivaldo Abreu, Vanderlino Assunção, pelo convívio e colaboração. Aos 
técnicos Vlademir e Luciano, do Laboratório de Física do Solo e ao Gilmar Gerigdon (laboratorista da Irrigação e Drenagem).

Ao amigos do curso de Solos e Nutrição de Plantas, Claudia Teixeira, Gloria Freitas, Jean Dalmo Marques, José Fernandes, José Ronaldo, Luciana Castro, Ana Regina Valcilene e Cássia Morais, pela amizade, cooperação mútua e pelos estímulos para alcançar os nossos objetivos.

As minhas irmãs de coração, Edvanda Rocha, Lucieta Martorano e Sylvia Farias.

Ao curso de Agrometeorologia que me acolheu com carinho. Aos professores (Nilson Villa Nova, Luiz Angelocci, Antonio Roberto Pereira e Paulo Sentelhas); e aos amigos que fiz (Sylvinha Farias, Rafael Costa, Késia da Silva, Evandro Righi, Karen Matos, Glauco Rolim, Alailson Santiago e Fábio Marin), pelo exemplo de amizade e solidariedade.

A todos os colegas da pós-graduação da ESALQ/USP, pelo convívio;

Aos professores e amigos do Curso de Agronomia de Cruz das Almas/ EAUFBA, pelo início de minha formação acadêmico-científica.

Aos amigos sempre presentes, Edvanda Silva Rocha, Dr. Gilson de Oliveira Rezende (In-memoriam), Regma Xavier, Kátia Amoedo, Seu Alberico Santana, Neto, Isolina, Genélicio Crusoe Rocha, Romário Gusmão e demais funcionários.

Ao CNPq, Conselho de Desenvolvimento Científico e Tecnológico, pela bolsa de estudos concedida.

A Comissão de Apoio a Vila Estudantil/USP pela concessão da moradia estudantil e aos amigos, pelo convívio.

A todos que diretamente ou indiretamente colaboraram para a realização deste trabalho, sinceramente agradeço. 


\section{SUMÁRIO}

página

ÍNDICES DE TABELAS ........................................................................................ vii

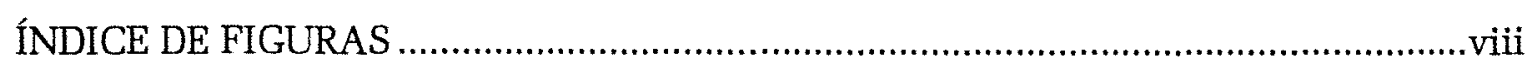

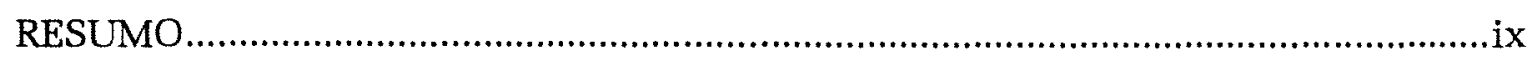

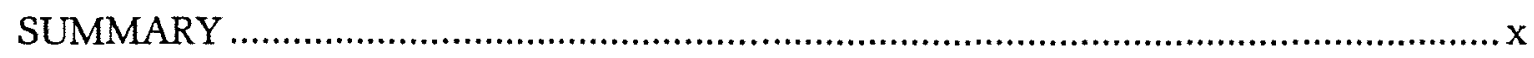

1 INTRODUÇÃ

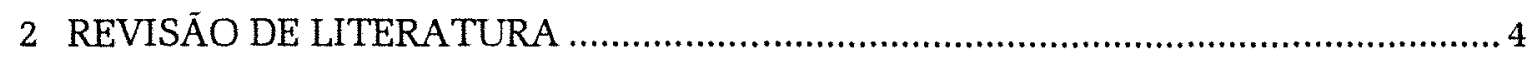

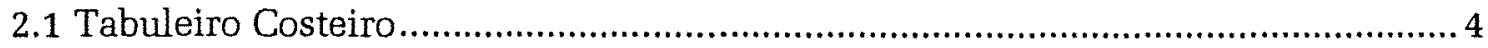

2.1.1 Influência das camadas adensadas nas características físico - hídrícas do

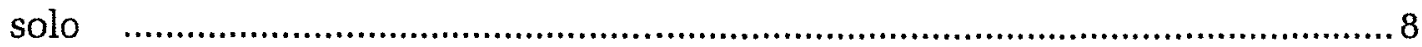

2.1.2 Retenção e condução de água no solo ................................................ 14

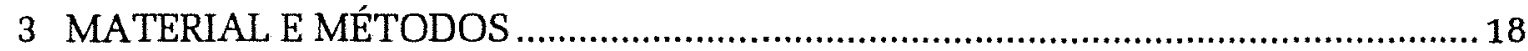

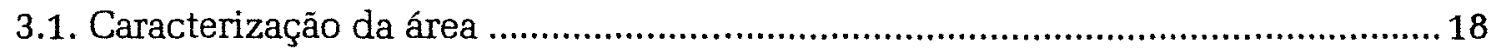

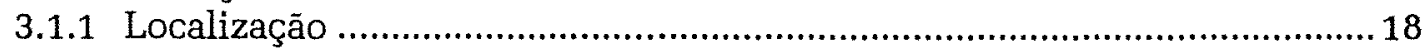

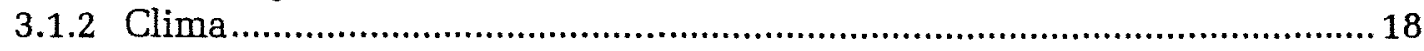

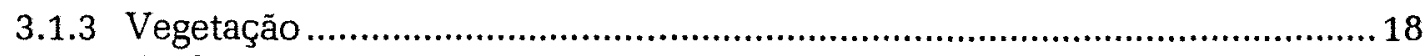

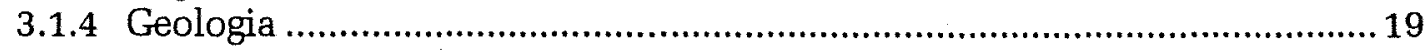

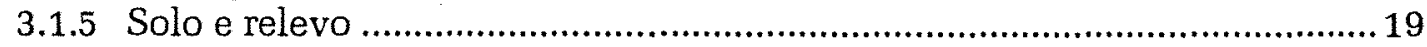

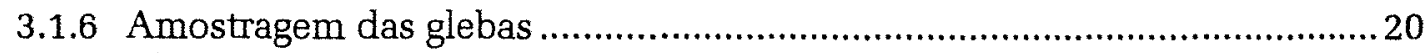

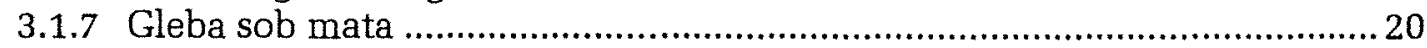

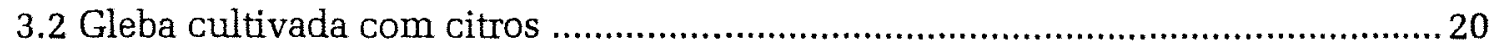

3.3 Gleba cultivada com mandioca............................................................... 21

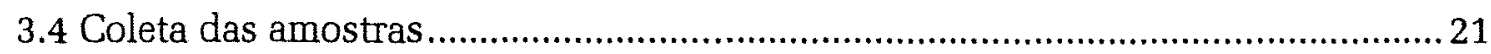

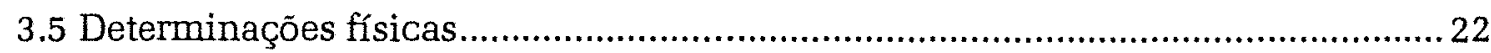

3.5.1 Granulometria e densidade dos sólidos ..............................................22

3.5.2 Umidade, densidade, porosidade e curva de retenção .............................2 23

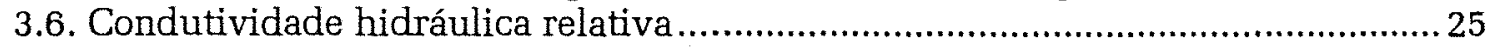

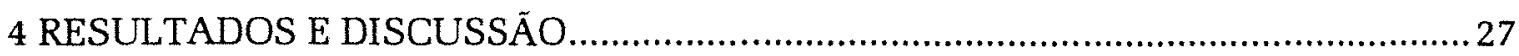

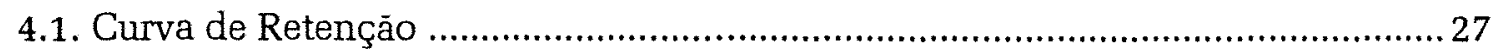

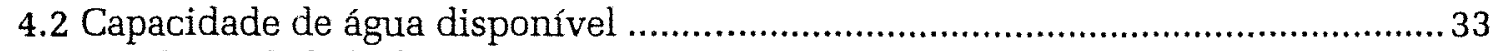

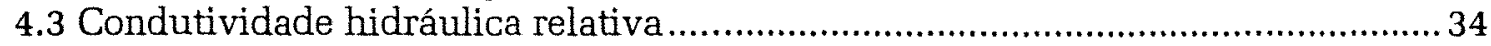

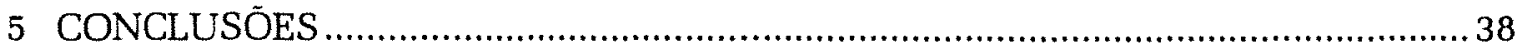

REFERÊNCIAS BIBLIOGRAFICAS ........................................................... 40

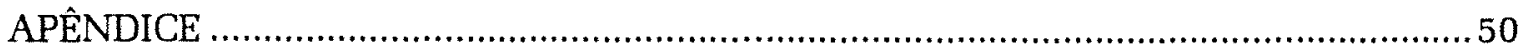




\section{ÍNDICE DE TABELAS}

Tabela 1 - Umidade volumétrica média e respectivos desvios padrões para as diversas tensões da curva de retenção do solo sob mata às profundidades de 0,10 e $0,30 \mathrm{~m}$.

Tabela 2 - Umidade volumétrica média e respectivos desvios padrões para as diversas tensōes da curva de retenção do solo sob citros às profundidades de 0,10 e $0,30 \mathrm{~m}$.

Tabela 3 - Umidade volumétrica média e respectivos desvios padrões para as diversas tensōes da curva de retenção do solo sob mandioca às profundidades de 0,10 e $0,30 \mathrm{~m}$

Tabela 4 - Valores médios de umidade volumétrica $\left(\theta \mathrm{kg} \mathrm{kg}^{-1}\right)$ nas diversas tensões $\left(\phi_{m} \mathrm{kPa}\right)$ e profundidades para três sistemas diferentes. ..... 31

Tabela 5 - Algumas características físicas de um Latossolo Amarelo coeso em diferentes sistemas e profundidades

Tabela 6-Capacidade de água disponível para as profundidades e tratamentos avaliados.

Tabela 7 -Valores de $m$ resultantes dos ajustes dos dados da Tabela 2 à equação de Van Genuchten (1980) para as profundidades e tratamentos avaliados. 


\section{ÍNDICE DE FIGURAS}

Figura 1 - Curvas de retenção da água num Latossolo Amarelo coeso com vegetação natural (mata), em duas profundidades.

Figura 2 - Curvas de retenção da água num Latossolo Amarelo coeso, cultivado com citros, em duas profundidades.

Figura 3 - Curvas de retenção da água num Latossolo Amarelo coeso, para a cultura da mandioca em duas profundidades. 36

Figura 4-Curvas de retenção da água num Latossolo Amarelo coeso, para diferentes sistemas e profundidades.

Figura 5-Condutividade hidráulica relativa em função da saturação relativa efetiva do solo para os três tratamentos à profundidade de 0,10 m (Mata 10, Citros 10 e Mandioca 10). 


\title{
RETENÇÃO DA ÁGUA EM SOLO SOB DIFERENTES USOS NO ECOSSISTEMA TABULEIROS COSTEIROS
}

\author{
Autora: JEANE CRUZ PORTELA \\ Orientador: PAULO LEONEL LIBARDI
}

\section{RESUMO}

O objetivo deste trabalho foi avaliar as curvas de retenção da água num Latossolo Amarelo álico coeso, do ecossistema Tabuleiros Costeiros sob duas condições de uso agrícola (citros e mandioca) e mata. As curvas foram determinadas em amostras de solo com estrutura indeformada, com 10 repetiçōes, às profundidades de $0,10 \mathrm{~m}$ e $0,30 \mathrm{~m}$ (aleatoriamente coletadas em cada tratamento). As tensões utilizadas foram 0,5, 1, 2, e $5 \mathrm{kPa}$ nos funis de placa porosa e 30, 70, 100, 500 e $1500 \mathrm{kPa}$ nas câmaras de pressão com placa porosa. Após a aplicação do teste de Tukey, ao nível de $5 \%$ de probabilidade, aos resultados obtidos, pôde-se verificar que houve redução da macroporosidade do solo com o cultivo e o manejo na cultura de citros. Esse fato, associado à determinação da condutividade hidráulica relativa leva a concluir que o solo com citros apresenta valores de condutividade hidráulica sempre inferiores que os da mata e mandioca. Além disso, verificou-se que o uso do solo com mandioca aumentou a capacidade de água disponível do solo a $0,10 \mathrm{~m}$ de profundidade em relação ao citros. Fato também relevante que depreende dos resultados é o de que, na área cultivada com citros a compactação foi mais intensa do que na cultivada com mandioca. Comparativamente a mata, o solo cultivado com citros reteu menos água a baixas tensões e apresentou conteúdos de água mais elevados a altas tensōes. 


\title{
WATER RETENTION IN A COASTAL TABLELAND ECOSYSTEM SOIL UNDER DIFFERENT USES
}

\author{
Author: JEANE CRUZ PORTELA \\ Adviser: PAULO LEONEL LIBARDI
}

\section{SUMMARY}

The objective of this research was to evaluate modifications in the quantity and quality of soil pores of a "Latossolo Amarelo" located in the Brazilian Coastal Tableland ecosystem under three management systems: natural forestry, cropped to citros and cropped to cassava. Soil water retention curves were determined with 10 replications using undisturbed soil samples (randomly collected in each treatment) submitted to tensions of $0.5,1.0,2.0$, and $5.0 \mathrm{kPa}$ (porous plate funnels) and 30.0, 70.0, 100.0, 500.0 and $1500.0 \mathrm{kPa}$ (porous plate pressure chambers). After the application of the Tukey test $(\mathrm{P}<0,05)$, it was possible to verify that there was decrease of the soil macroporosity in the soil cropped to citros. This fact, in association with the determination of the relative soil hydraulic conductivity, leads to a strong tendency that the soil with citros presents hydraulic conductivity values always smaller than those for the soil with forestry and cassava. Besides, it was also verified that the soil when cropped to cassava increased its soil water holding capacity at the $0.10 \mathrm{~m}$ soil depth, in comparison with the soil cropped to citros. A fact also relevant from the results was that the citros soil management compacted more intensively the soil than the cassava one; this caused a lesser water retention in the soil under citros than the soil under forestry at lower soil water tensions and more water retention than the forestry at higher tensions. 


\section{INTRODUÇÃO}

Os tabuleiros costeiros no Brasil são mapeados desde a Região Amazônica até o Rio de Janeiro, com possibilidade de estarem presentes também mais ao Sul. Esses tabuleiros ocorrem sempre "num conjunto" de solos característicos, onde os Latossolos coesos e os Podzólicos são os de maiores expressões geográficas.

Os solos da região dos tabuleiros costeiros, em sua maioria, apresentam, como principais limitações agrícolas, baixa capacidade de retenção de água e fertilidade natural. Embora considerados profundos, grande parte desses solos apresenta sua profundidade efetiva para o crescimento radicular reduzida devido à presença de horizontes coesos, o que agrava tais limitações. Essas camadas interferem nos fatores físicos do solo que atuam no desenvolvimento das plantas tais como potencial de água, aeração e resistência do solo à penetração das raízes, além de promoverem alterações na dinâmica da água no solo.

Uma característica marcante em muitos desses solos é a presença de uma camada coesa, com espessura média entre $0,2 \mathrm{~m}$ e $0,6 \mathrm{~m}$, geralmente localizada nos horizontes de transição $\mathrm{AB}$ ou $\mathrm{A}$, podendo, no entanto, atingir os horizontes Bw ou Bt. A presença dessas camadas endurecidas tem como conseqüências o impedimento à circulação de água e ar no solo e à penetração de raízes e a formação sazonal de lençol de água suspenso gerando desoxigenação temporária nos horizontes superficiais.

O coeso é observado tanto no solo sob mata quanto sob cultivo, levando a crer que a presença do horizonte coeso não está unicamente relacionada ao 
manejo do solo, mas, principalmente, a mecanismos genéticos de formação dos solo.

Na região de Cruz das Almas e cidades vizinhas há o predomínio da exploração agrícola. Com a decadência da cultura do fumo, a cultura da mandioca passou a dominar em todos os municípios. É de grande importância, também, o cultivo de frutíferas como a laranja, a banana, a manga, o mamão e o maracujá.

As espécies vegetais, anuais e perenes, no ecossistema tabuleiros costeiros, mesmo com irrigação suplementar, geralmente apresentam baixo vigor vegetativo e baixas produções em comparação com outros ecossistemas, indicando a possibilidade de uma relação solo - planta fortemente influenciada pela baixa fertilidade, acidez elevada e pela estrutura dominante dos horizontes coesos.

Os solos coesos dos tabuleiros costeiros têm grande importância, sobretudo na Região Nordeste, pelos seguintes aspectos: representam grandes áreas localizadas próximas a grandes centros consumidores urbanos, na faixa úmida costeira onde as precipitações são regulares, sem os problemas de secas periódicas que ocorrem na área do Sertão e do Agreste. A topografia favorável e a infraestrutura de apoio nessas regiões as torna de grande potencialidade para a produção de alimentos.

Portanto, o conhecimento detalhado desses solos, no que respeita às transformações de suas propriedades físicas, após a implantação de culturas agrícolas como mandioca e citros, é de fundamental importância na definição de futuras práticas de cultivo e manejo desses solos.

Os resultados ampliam a avaliação para porosidade, $K_{r}, D_{s}$, além da retenção de água.

Desta maneira, o objetivo deste trabalho é avaliar as curvas de retenção da água num Latossolo Amarelo coeso sob três sistemas de produção, (mata, 
mandioca e citros), determinadas em amostras de solo com estrutura indeformada. 


\section{REVISÃO DE LITERATURA}

\subsection{Tabuleiro costeiro}

Os solos da região dos tabuleiros costeiros, em sua maioria, são derivados de sedimentos do Grupo Barreiras do Terciário e apresentam, como principais limitações agrícolas, baixa capacidade de retenção de água e nutrientes. Embora considerados profundos, grande parte desses solos apresenta sua profundidade efetiva reduzida por horizontes coesos, o que agrava tais limitações.

O termo Barreiras vem sendo usado na literatura geológica brasileira ora como Formação, ora como Grupo, ora como Série, para designar sedimentos de origem continental, pouco consolidados, geralmente sem fósseis que permitam atribuir-lhes uma idade correta. Comumente, admite-se a idade Plio - Pleistocênico para esses sedimentos embora seja provável que eles contenham ou encerrem depósitos mais antigos e também mais modernos, abrangendo um intervalo de tempo que começaria no Cretáceo superior até o quaternário, segundo Matoso e Robertson (1959).

Os solos originados dos sedimentos do Grupo Barreiras ocupam uma extensa faixa de terra ao longo da costa brasileira, que se inicia no Estado do Rio de Janeiro e estende-se ao Pará e Baixo Amazonas, até a divisa com a Colômbia, Peru e Bolívia, com possibilidade de estarem presentes também mais ao sul. Estima-se que no Brasil, os solos desenvolvidos de sedimentos do tipo Barreiras abranjam uma extensão de terra da ordem de $200.000 \mathrm{~km}^{2}$ (Jacomine, 1996). Para os Estados do Nordeste Brasileiro, são considerados entre as terras com melhor aptidão climática e topográfica para agricultura. 
Constituem-se em uma das maiores ocorrências de sedimentos terciários do mundo (Almeida, 1964).

A importância social e econômica deste ecossistema é refletida pelas grandes concentrações urbanas, infra-estrutura de transporte e grande diversidade agrícola. De acordo com o zoneamento agroecológico do Nordeste realizado pela EMBRAPA/Centro de Pesquisa Agropecuária do Trópico SemiÁrido-CPATSA/Centro de Pesquisa de Solo/CNPS, Silva (1993), a unidade geoambiental é definida como "uma entidade espacial, na qual o substrato, a vegetação natural, o modelado, a natureza e a distribuição dos solos, em função da topografia, constituem um conjunto homogêneo, cuja variabilidade é mínima, de acordo com a escala cartográfica". As unidades geoambientais agrupadas com base nas características morfoestruturais e / ou geomorfológicas e/ou geográficas, compõem as unidades de paisagem, categoria esta, em que se enquadram os tabuleiros costeiros.

Na faixa sedimentar costeira do Brasil é possível distinguir quatro unidades de paisagem: baixada litorânea, superfícies terciárias dos baixos platôs costeiros, também denominadas tabuleiros costeiros ou simplesmente tabuleiros, superfícies terciárias muito dissecadas e bacia cretácea (Empresa Brasileira de Pesquisa Agropecuária, 1975).

Apesar do grande potencial agrícola e do mercado nas áreas dos Tabuleiros, há uma demanda reprimida por produtos agrícolas e as atividades agropecuárias tem sido, em geral, inviabilizadas pelas baixas produções e alta relação custo/beneficio (Cintra et al., 1997). As camadas coesas (caráter pedogenético) dos solos dos tabuleiros, têm se constituído como principal limitante do meio físico, seguindo o clima com a má distribuição das chuvas, que se concentram por $80 \%$ num período de seis meses contínuos, em muitas áreas do ecossistemas. A quase totalidade da fração areia é composta por quartzo (BRASIL, 1976), indicando praticamente ausência de reserva de 
nutrientes. Dentre as causas que fazem dos solos de Tabuleiros áreas pouco usada em agricultura ressalta-se a qualidade das suas terras (UFV, 1984).

As etapas da fase de preparo do solo, os sistemas de irrigação, os cultivos intensivos, o uso inadequado de máquinas e implementos, provocam a destruição do que se tem de matéria orgânica e, em muitos casos, revirando e misturando camadas coesas dos horizontes $\mathrm{A}$ e $\mathrm{B}$ e expondo material coeso do horizonte B.

Oliveira et al (1968), Aguiar Neto e Nacif (1988) e Leão e Melo (1990) sugerem que o adensamento observado nos solos de "Tabuleiros" é resultante da migração de colóides da camada superficial, provocando a obstrução dos poros e, consequentemente, a diminuição da permeabilidade e da aeração dos mesmos.

Jacomine (1974), admite que os fenômenos físicos são os principais responsáveis pela gênese dos fragipans (assim ele denomina os horizontes coesos) em solos de "Tabuleiros" do Nordeste. Para o autor, a translocação do material da superfície do solo (ácido de silício, alumínio livre e argila), associada a processos de umedecimento e secagem, e também à formação de corpos estáveis (concreções), produzem pressões que atuam gradativa e desigualmente comprimindo a massa de solo, provocando dessa forma uma reorganização das partículas.

A formação dessas camadas tem sua origem atribuída a causas genéticas, ponto comum entre os pesquisadores que estudam este tema e está associada a processos diversos entre os quais, a translocação de consideráveis porçōes de argila das camadas superficiais para as subjacentes, processo este denominado argiluviação (Ribeiro, 1991). À ação de compostos húmicos pouco polimerizados os quais geram degradação dos minerais argilosos e migração de sílica, alumínio e ferro (Ribeiro, 1993) e, à alternância de ciclos de umedecimento e secagem promovendo o adensamento por dessecação com 
transformações laterais pela dinâmica dos fluxos de água lateral e basal (Moniz, 1996). Pode estar associado a este último processo, a desidratação dos agentes cimentantes, com a consolidação da argila no período de seca, seguida da implosão dos agregados devido ao aumento da pressão interna de ar, quando o solo umedece (Harris et al. citado por Freitas e Blancaneaux, 1990). Esse último processo faz parte da gênese de diversos solos e não foi diretamente relacionado, pelo autores, à gênese dos solos de tabuleiro.

A coesão ocorre tanto nas áreas sob floresta como nas áreas sob cultivo; por isso, não se pode considerar este fenômeno como herança de manejo, parecendo tratar-se de um processo de transformação do material de origem (Ribeiro, s/d).

Do ponto de vista climático, para Foury (1966), os Tabuleiros constituem uma subdivisão da zona climática denominada Zona Litorânea, que se caracteriza por um clima tropical úmido, porém com uma estação seca bem definida e geralmente quente.

A distribuição desses solos no Brasil foi observado sob clima que vai desde o semi-árido até o equatorial. Observou-se também, sobre as mesmas variadas coberturas vegetais, indo desde a caatinga até a floresta equatorial. $\mathrm{O}$ relevo entretanto é sempre do tipo tabuleiros. Também são conhecidos os tabuleiros desenvolvidos sobre diversos tipos de sedimentos, como alguns existentes na bacia sedimentar do Recôncavo Baiano, de idade cretácea, que pode entretanto apresentar coberturas totais ou parciais dos sedimentos encontram-se sotoposto discordantemente sobre Formação cretáceas (Alheiros et al., 1988).

Os latossolos Amarelos foram definidos pelo projeto RADAMBRASIL (1981), folha de Salvador, como latossolo amarelo álico e distrófico, que são solos minerais, ácidos, não hidromórficos, com horizonte B latossólico álico, que corresponde em parte ao horizonte óxido, da classificação americana. 
Caracterizam-se por um estágio de intemperização constituindo por sesquióxidos, minerais de argila (1:1) e minerais primários resistentes ao intemperismo. Possuem ainda, como característica do seu avançado grau de intemperismo, baixa relação silte / argila e baixa relação molecular $\mathrm{SiO}_{2} / \mathrm{Al}_{2} \mathrm{O}_{3}$ (Ki). Apresentam baixos valores para capacidade de troca de cátions (valor T), na fração argila (argila de atividade baixa). Esses solos na região apresentam geralmente um aumento de argila natural (dispersa em água). Quanto à distribuição dos solos, os de maior expressão são os Latossolos Amarelos, Podzólicos Amarelos e Acinzentados, Areias Quartzosas e Podzóis.

\subsubsection{Influência das camadas adensadas nas características físico - hídricas do solo}

A ocupação humana, combinada à friabilidade litológica favorece a aceleração dos processos morfodinâmicos, nesta unidade de paisagem, contribuindo para o agravamento da lixiviação e movimento de massas nos solos imprimindo, em alguns trechos da paisagem caráter bastante instável. Esta instabilidade, facilmente perceptível através do desenvolvimento de ravinamentos nas encostas mais íngremes (Brasil-Ministério das Minas e Energia, 1983), se percebe também pelo desaparecimento de espécies vegetais e pela intensificação do processo erosivo. A este respeito Silva (1991), ressalta a ação do desmatamento sobre o quase total desaparecimento de várias espécies vegetais nobres da Mata Atlântica nos tabuleiros costeiros do extremo sul da Bahia, como também, sobre a degradação da camada superficial do solo, intensificação do adensamento e perdas de solo por erosão. É provável que na sua origem, os tabuleiros costeiros tenham sido ocupados por florestas tropicais subperenifólias, vegetação típica da Mata Atlântica e por vegetação de cerrado, nos solos mais arenosos.

O meio físico representado, principalmente, pelas camadas coesas e o regime climático caracterizado pela alta concentração das chuvas e presença de período prolongado de seca, são os principais responsáveis pelos problemas 
associados à exploração agropecuária nesse ecossistema. Historicamente, no entanto, esses problemas têm sido mascarados, ao longo do tempo, em virtude da paisagem aparentemente favorável ao uso agrícola como relevo adequado à mecanização, volume elevado de precipitação pluvial total e grande profundidade do solo. Nos tabuleiros onde existem camadas coesas e longos períodos de déficit hídrico, as vantagens mencionadas deixam de existir devido não só ao impedimento à penetração das raízes e conseqüente redução da profundidade efetiva do solo, como também, à formação de zonas temporárias de encharcamento durante a estação chuvosa. Nestas circunstâncias, os solos ficam altamente vulneráveis ao regime climático, passando do estágio excessivamente úmido, no período chuvoso, para excessivamente seco quando as chuvas escasseiam, submetendo as raízes das plantas, em geral superficializadas, a condições de má aeração ou completa ausência de umidade. Os parâmetros climáticos exercem influência sobre todos os estágios da cadeia de produção agrícola, incluindo o preparo do solo, a semeadura, o crescimento dos cultivos, a colheita, o armazenamento, o transporte e a comercialização (Ayoade, 1996).

O solo é o reservatório de água para as plantas, e todas as práticas de manejo de água em agricultura visam à manutenção de seu nível de água em condições ideais para o desenvolvimento das culturas. Apesar de ser um reservatório aberto para a atmosfera e para os horizontes mais profundos do perfil, ele retém água através de sua interação com a matriz do solo (Reichardt, 1988).

A dinâmica da água no solo, vital para o crescimento $\mathrm{e}$ desenvolvimento das espécies vegetais, é um dos principais fatores afetados pela presença de camadas coesas nos solos de tabuleiro na medida em que impōem grandes alteraçōes no fluxo de água e ar e na magnitude dos fatores físicos diretamente relacionados com o crescimento dos plantas: potencial da água no solo, aeração, temperatura e resistência à penetração de raízes (Letey, 
1985). Este é um dos motivos pelo qual este tema consta como uma das principais linhas de pesquisa no documento de compatibilização das propostas de pesquisa oriundo da Reunião Técnica sobre Solos Coesos dos Tabuleiros Costeiros (1996).

A substituição das matas naturais por culturas agrícolas vem ocorrendo ao longo dos anos. A mudança na vegetação causa um desequilíbrio no ecossistema, modificando as propriedades do solo, cuja magnitude varia com as condições de clima, espécies vegetais e natureza do próprio solo. Os solos respondem de forma diferente aos diversos sistemas de cultivo, manejo e tempo de uso. Estas respostas são quantificadas através da avaliação das modificações nas suas propriedades físicas, químicas e microbiológicas (Godefroy \& Jacquin, 1975).

As alterações nas propriedades químicas do solo, após a retirada da mata natural e a introdução de novas culturas, dependem de vários fatores, como a classe de solo, a sua fertilidade inicial, o comportamento físico-químico de cada nutriente, suas interaçōes com o meio, a cultura introduzida, como também o manejo e os tratos culturais adotados.

Cunningham (1963), pesquisando o efeito da retirada da mata sobre a dinâmica dos nutrientes em solos tropicais, constatou diminuição nos teores de carbono orgânico, nitrogênio, fósforo e capacidade de troca catiônica. Isto ocorreu em razão do aumento da temperatura do solo, proporcionando rápida decomposição da matéria orgânica e à não reposição da mesma.

Da mesma forma, Coelho (1990) observou que a ciclagem de nutrientes na camada de solo de cerrado sob vegetação nativa foi eficiente na manutenção de condições químicas mais favoráveis ao desenvolvimento vegetal. Também, verificou que o cultivo do solo promoveu maior distribuição de bases em profundidade. 
O cultivo do solo, de modo geral, modifica suas propriedades físicas, pois mesmo as práticas culturais mais simples, como as capinas manuais, podem proporcionar a pulverização de sua superfície (Russel \& Russel, 1961). As propriedades físicas dos solos deterioram-se, geralmente, quando os mesmos são cultivados intensamente (Skidmore et al., 1975; Juo \& Lal, 1977; Coote \& Ramsey, 1983).

As características físicas de um solo são modificadas de acordo com o tipo de uso e cultivo a que o mesmo é submetido. Algumas mudanças ocorrem num período curto de tempo ou mesmo em uma simples prática de preparo; outras, apenas com o manejo continuo, serão visíveis ou mensuráveis. Assim, se as relações de massa e volume de solo na camada arável variam a cada revolvimento, a degradaçāo da estrutura é reduzida (Vieira, 1981).

A densidade do solo é uma propriedade relativamente instável, variando de solo para solo e dentro de um mesmo solo, em função principalmente, do grau de compactação, do teor de matéria orgânica do solo, da ausência ou presença de cobertura vegetal, do sistema de cultivo empregado e da profundidade e época de amostragem (Kiehl, 1979); Brady, (1989).

A densidade do solo também é afetada pela substituição da vegetação nativa por culturas, ou seja, torna-se maior em solos cultivados (Aina, 1979; Silva, 1981; Coote \& Ramsey, 1983; Fialho, 1985; Neves et al. 1991). Silva (1981) constatou, em Latossolo Amarelo do sul do Estado da Bahia, aumento da densidade do solo quando mecanizado em relação aquele sob vegetação de floresta, devido à destruição da estrutura do solo provocada pelo uso de máquina pesada. Já em um Podzólico Vermelho-Amarelo, Saraiva (1987) verificou diminuição da densidade nos solos onde se procedeu a aração, em relação à testemunha em pousio, bem como aumento da porosidade total e da macroporosidade. 
Segundo Baver (1966), a variação da porosidade total é função do tamanho de partículas e grau de agregação, tendo a matéria orgânica papel importante, pois favorece a formação de grandes agregados, como conseqüência maior porosidade total. Para Grohman (1972), dentre as propriedades físicas do solo, sujeitas às alterações pelo cultivo, a porosidade total, por estar relacionada com volume e distribuição dos espaços porosos, merece especial atenção, visto que nesses espaços se processam os principais fenômenos que regulam o crescimento e a produção vegetal.

Por outro lado, Machado et al.(1981), comparando as propriedades de um solo sob cultivo convencional com as de outro sob vegetação de mata virgem, verificaram que somente a partir do oitavo ano de cultivo havia alteração na densidade, na porosidade total e na macro e microporosidade. Além disso, as alterações mais evidentes foram observadas somente no décimo quarto ano de cultivo, mostrando alto grau de compactação do solo.

$\mathrm{Na}$ região citricola do Recôncavo Baiano, Cintra \& Coelho (1987), avaliando as condições físicas do solo em função do manejo adotado, observaram nos locais onde a prática da adubação era usual, maior agregação do solo devido, provavelmente, aos maiores teores de matéria orgânica.

Nos solos sob cultivo, principalmente nas camadas superficiais, o aumento de microagregados está relacionado à destruição da macroestrutura pelo efeitos do preparo do solo e do impacto da gota de chuva. Segundo Tisdall \& Oades (1982) a boa estrutura para o crescimento das plantas depende da presença de agregados de 1 a $10 \mathrm{~mm}$ de diâmetro e que permanecem estáveis quando molhados.

Cintra et al. (1983), caracterizando fisicamente o solo de um pomar de laranja "Baianinha" submetido a diferentes práticas de manejo, verificaram que o uso contínuo e a longo prazo de grade e herbicida resultou na formação de camadas compactadas em superfície e subsuperfície. Concluıram que o uso de 
roçadas na entrelinha manteve ou melhorou as propriedades físicas do solo. No entanto, Pacheco et al. (1975) verificaram, em um Latossolo Vermelho Amarelo fase cerrado, também sob pomar de laranja "Baianinha", que a vegetação natural ceifada e a soja perene ceifada reduziram, tanto o crescimento quanto a produção da laranja. A competição para a água do solo, entre as plantas de cobertura e as laranjeiras, foi a principal causa do insucesso das coberturas vivas permanentes. Por isto, Cintra et al. (1983) recomendam a ceifa no período das chuvas associadas à gradagem no verão, considerando-se a ocorrência, na região do recôncavo Baiano, de período com elevado déficit hídrico.

A densidade do solo influência de forma direta a resistência do solo à penetração de raízes e, de forma inversa, a difusão de oxigênio. Nos latossolos com camadas adensadas do Estado de Pernambuco, Oliveira (1967) constatou maior densidade nestas camadas, associada a menores volumes de macroporos e coeficientes de permeabilidade; essas condições levaram à saturação e encharcamento da camada superficial do solo. Taylor \& Gardner (1963) verificaram, na cultura do algodoeiro, maior dificuldade de penetração do sistema radicular com o aumento da densidade do solo.

Cintra \& Cunha (1987), comparando as propriedades físicas do solo sob mata e sob cultura de abacaxi, este com diferentes tempos de utilização, verificaram que, apesar do manejo inadequado do solo, não houve alterações significativas nas suas propriedades físicas. Constataram que os benefícios introduzidos com a adição de matéria orgânica no plantio da cultura do abacaxi compensaram os possíveis problemas decorrentes do tempo de uso e do manejo inadequado do solo.

Com relação as principais limitações ao uso agrícola dos solos de Tabuleiros, Souza (1996) afirma que, apesar destes solos serem considerados profundos, possuem uma pequena profundidade efetiva. Isto resulta da presença de horizontes coesos e adensados, com reflexos na dinâmica da água 
no perfil e, principalmente o aprofundamento do sistema radicular, influenciando negativamente o desenvolvimento vegetal. Para Demattê (1981), o processo de adensamento interfere na densidade do solo, porosidade e sua distribuição relativa, podendo restringir o movimento da água, a aeração do solo e o desenvolvimento radicular. Entre outras limitações, ressalta-se a baixa fertilidade natural, aumento da acidez em profundidade, baixa CTC, saturação de bases e capacidade de retenção de água.

A substituição da vegetação nativa pelo uso agrícola pode intensificar o adensamento desses horizontes. Melo Neto (1978), citado por Fonseca (1986), observou em um latossolo de textura argilosa, que a substituição da vegetação natural primitiva por capoeira, cultura de cana-de-açúcar, eucalipto ou pastagem, resultou em uma diminuição da porosidade, da água disponível, do teor de argila, argila natural e diminuição da densidade do solo, como conseqüência da degradação da estrutura do solo.

A adoção de sistemas de manejo agrícola racionais pode reverter a degradação das características físicas do solo. Por exemplo, Maia (1996) mostrou que a utilização do cultivo mínimo, após 9 anos de cultivo convencional, melhorou as características físicas do horizonte A de um Latossolo Vermelho Escuro, localizado no município de Diamantina - MT. Tal manejo favoreceu a distribuição de raízes até a profundidade de $0,40 \mathrm{~m}$, com reflexo direto no rendimento de grão de soja cultivada em sequeiro. A velocidade de infiltração foi melhorada, sendo o total de água infiltrada após 120 minutos, 5 vezes superior ao cultivo convencional.

\subsubsection{Retenção e condução de água no solo}

A água é retida no solo devido a fenômenos de capilaridade e adsorção. A capilaridade tem maior importância na retenção de água no solo na faixa úmida, quando os poros se apresentam razoavelmente cheios de água. Sob secamento, os poros vão se esvaziando e filmes de água recobrem as partículas 
solidas: nestas condições, o fenômeno de adsorção passa a dominar a retenção de água (Baver, 1966; Forsythe,1975).

Os dois parâmetros básicos do binômio água - solo são o teor de água no solo e seu estado de energia. Eles são interdependentes, podendo oscilar dentro de amplos limites, variando basicamente em função da textura, estrutura, distribuição dos diâmetros de poros do solo (Hillel, 1970; Kiehl, 1979: Reichardt, 1985).

O potencial total de água no solo é função de vários fatores. O principal deles é a granulometria, que determina a área de contato entre as partículas sólidas e a água e, ainda, determina as proporções de poros de diferentes tamanhos. A estrutura é outro fator que exerce grande influencia no potencial total de água no solo, pois ela determina a distribuição de diâmetro de poros (Hillel, 1970: Reichardt, 1985: Yoshida, 1991).

O potencial mátrico da água no solo $\phi_{m}$, é resultado de forças capilares e de adsorção que surgem devido a interação entre a água e as partículas sólidas, isto é, com a matriz do solo. Estas forças atraem e fixam a água no solo, diminuindo sua energia potencial em relação a água livre (Reichardt, 1985). Deste modo, o valor de $\phi_{m}$ é função da umidade da matriz sólida, sendo o seu valor sempre negativo. A exceção ocorre quando o solo apresenta-se saturado, com $\phi_{m}$ igual a zero. Um gráfico relacionando a umidade do solo com o potencial mátrico denomina-se curva de retenção da água no solo. Esta curva, feita de maneira completa e utilizando amostras de solo com estrutura indeformada é um dos melhores índices para analisar o efeito das práticas de manejo no comportamento da retenção da água nos poros do solo (Moraes et al. 1993) e é, sem dúvida, fundamental na caracterização física de um solo.

Rivers \& Shipp (1978) e Hillel (1982), salientam que o teor de água retida a baixas tensões depende primeiramente do efeito da capilaridade e da porosidade, portanto, é fortemente afetada pela estrutura do solo. Por outro 
lado, a retenção a altas tensões é devido ao incremento na adsorsão e, menos influenciada pela estrutura e mais pela textura e superfície especifica do solo. Consequentemente quanto maior a conteúdo de argila, em geral maior a retenção de água a uma dada tensão, sendo a inclinação da curva mais gradual. Em um solo, a distribuição de poros por tamanho é mais uniforme e mais água é adsorvida, tanto que um aumento na tensão resulta em decréscimo no teor de água.

Muitos pesquisadores, ao considerarem a importância do movimento e armazenamento da água no solo, vêm se dedicando ao estudo do processo de infiltração e determinação de parâmetros hídricos como condutividade hidráulica e difusividade da água, fundamentais na determinação do fluxo da água no solo. Segundo definição de Hillel (1970), o movimento da água no solo é resultante do gradiente de potencial total, o qual ocorre no sentido decrescente e cuja intensidade é afetada pelo meio físico, principalmente pelas propriedades geométricas do solo em que ocorrerá o movimento. Este efeito do solo sobre o movimento da água, é chamado condutividade hidráulica, definida por Libardi (1995), com um "coeficiente que expressa a facilidade com que um fluido é transportado através do meio poroso e que depende tanto das propriedades do meio como das do fluido".

Cassel e Nielsen (1986) definem a capacidade de armazenamento como a diferença entre o conteúdo de água entre a capacidade de campo e o ponto de murcha. Capacidade de campo é a água retida em um solo úmido, após a drenagem por gravidade, por num certo período de tempo. A capacidade de campo não é uma constante, mas geralmente assume que ela corresponde ao conteúdo de água no solo retido a um potencial matricial de $-33 \mathrm{kPa}$. O ponto de murcha permanente no qual as plantas não se recuperam, geralmente corresponde a um potencial matricial de $-1500 \mathrm{kPa}$ (Kern 1995).

Mota (1995), estudando um Latossolo Amarelo no município de Cruz das Almas (BA), avaliando a variação do potencial total da água sob diferentes 
sistemas de preparo, afirma que no período chuvoso, não foram observadas grandes diferenças no potencial total da água no solo. No período seco, os tratamentos de subsolagem + arado de aiveca tenderam a permanecer mais tempo com potenciais mais altos, significando um maior conteúdo de água no solo.

Paiva (1997), estudando a dinâmica da água em uma topossequência de solos de tabuleiros do estado da Bahia e sua implicação no crescimento da laranjeira verificou que o Podzólico Acinzentado apresentou maiores valores de condutividade hidráulica saturada do que os outros dois solos. No latossolo amarelo podzólico e no podzólico amarelo os menores valores de condutividade hidráulica saturada foram aqueles apresentados pelos horizontes coesos.

Pettersen et al (1968) indicam que às baixas tensões a matéria orgânica tem um efeito indireto na retenção de água devida à influência na agregação de partículas sólidas no solo e, a altas tensões tem uma atuação direta em função de sua elevada superfície e capacidade de adsorção.

Cintra (1997) desenvolveu um estudo que serve de subsídio para esclarecer esses pontos e outros estudos como o consumo de água pelas culturas em solos dos Tabuleiros Costeiros. Neste trabalho, entre outros estudos, foi desenvolvido um balanço hídrico completo num solo de Tabuleiro Costeiro, cultivado com citros da região de Aracaju (Sergipe), durante o período de um ano e verificou-se que, pelo fato de a camada coesa existente, no solo estudado, atuar como barreira física às perdas de água do solo, no momento em que as chuvas escasseiam. Desta forma, ela funciona como regulador do suprimento de água para as plantas nos meses de maior demanda hídrica dos citros que precedem a estação chuvosa. 


\section{MATERIAL E MÉTODOS}

\subsection{Caracterização da área}

\subsubsection{Localização}

A área em estudo está localizada no Município de Cruz das Almas (BA), EMBRAPA /Centro Nacional de Pesquisa de Mandioca e Fruticultura Tropical (CNPMF), região do Recôncavo Baiano, no planalto pré-litorâneo, cujas coordenadas geográficas são de $12^{\circ} 40^{\prime} 19^{\prime \prime}$ de latitude sul, $39^{\circ} 06^{\prime} 22^{\prime \prime}$ de longitude oeste e altitude média de 220 metros.

\subsubsection{Clima}

O clima da região, segundo a classificação de Thornthwaite, é do tipo $\mathrm{C}_{1}$, seco e sub-úmido. A pluviosidade média anual, no período de 1949 a 1990, esteve em torno de $1200 \mathrm{~mm}$. Os meses mais chuvosos, em condições normais, são abril e maio (150 $\mathrm{mm}$ ) e os mais secos, setembro e outubro (60 $\mathrm{mm}$ de precipitaçāo pluvial). A umidade relativa média do ar é de aproximadamente $81 \%$ e a temperatura média máxima está em torno de $28^{\circ} \mathrm{C}$ (EMBRAPA, 1991).O balanço hídrico do Município de Cruz das Almas, determinado por Carmo (1973), no período de 1949 a 1972, mostra excedente hídrico de $90 \mathrm{~mm}$ no inverno, concentrando-se no mês de julho e déficit hídrico de $221 \mathrm{~mm}$, notadamente nos meses de janeiro e fevereiro.

\subsubsection{Vegetação}

Floresta Estacional Semidecidual cobria originalmente os solos próximos a Cruz das Almas e Feira de Santana. Atualmente a vegetação 
encontra-se bastante alterada, com maior parte das áreas ocupadas por culturas implantadas: pastagens, culturas de subsistência e frutíferas perenes, além de vegetação secundária, entre as quais Shinopsis brasiliensis (Braúna), Goniorrhachis marginata (Itapicuru), Mimosa malacocentra (Calumbi), Croton $s p$ (Marmeleiro) e Syagrus vagans (Licurioba) (SOCIEDADE BRASILEIRA DE CIÊNCIA DO SOLO, 1981).

\subsubsection{Geologia}

Segundo Ribeiro (1991), os solos da região são formados por depósitos sedimentares terciários da Formação Capim Grosso, assentados discordantemente sobre rochas pré-cambrianas do complexo granulítico. A Formação Capim Grosso é constituída por rochas detrativas mal consolidadas, ou seja, arenitos amarelos avermelhados, sílticos argilosos, mal selecionados e também argilosos.

\subsubsection{Solo e relevo}

Na região, os solos são conhecidos como "tabuleiros", correspondendo aos baixos platôs costeiros. Predomina o Latossolo Amarelo álico, apresentando horizontes subsuperficiais coesos. O relevo é plano, inferior a $0,03 \mathrm{~m} \mathrm{~m}^{-1} \mathrm{de}$ declividade. $\mathrm{Na}$ área em estudo o solo pertence à classe textural franco-argiloarenoso. Conta com um horizonte superficial mais arenoso, com aproximadamente $0,74 \mathrm{~kg} \mathrm{~kg}^{-1}$ de areia; além disso, o teor de argila aumenta em profundidade. Segundo EMBRAPA (1999), Latossolos Amarelos Coesos são solos com um ou mais horizontes com espessura mínima de $0,30 \mathrm{~m}$, que não satisfaz os critérios para fragipã ou duripan, compreendendo o horizonte $A B$ e/ou BA, e/ou parte do Bw, os quais secos são muito resistentes à penetração do martelo pedológico ou trado e que não apresentam uma organização estrutural visível (são maciços) e que se desfaz em agregados com consistência a seco, no mínimo, dura. A consistência úmida varia de friável a firme; a densidade do solo deste horizonte e mais elevada que os horizontes subjacentes. A saturação 
por base é baixa $(\mathrm{V}<50 \%)$, o teor $\mathrm{Fe}_{2} \mathrm{O}_{3}$ (ataque sulfúrico) é menor que $8 \%$ e o Ki é 1,7 ou maior.

\subsubsection{Amostragem das glebas}

O estudo consta de diferentes coberturas vegetais, ou seja, três glebas distintas, uma com vegetação natural (mata) e as demais cultivadas com citros e mandioca. A gleba sob mata foi utilizada como referência, para avaliar as modificações nas demais glebas, decorrentes da presença das citadas culturas. As glebas sob cultivo estão situadas na Estação Experimental do Centro Nacional de Pesquisa de Mandioca e Fruticultura Tropical (CNPMF), enquanto a gleba sob mata está localizada na entrada da cidade, distando aproximadamente $3 \mathrm{~km}$ do CNPMF.

\subsubsection{Gleba sob mata}

Constitui-se de uma reserva natural pertencente à Prefeitura Municipal, localizada na entrada de Cruz das Almas.

Segundo Melo Filho \& Araújo Filho (1984), a vegetação primária é uma transição floresta subperenifólia/subcaducifólia, com predominância das espécies: Jacarandá, Camaçari, Giquitibá, Cedro, Baba de boi, Aipim, Tripa de abóbora, Baraúna de espinho, Itapicuru preto e amarelo, Vinhático, Ipê amarelo, Pau d'arco, Murta, Sapucaia, Piquiá, Fava caboclo, Jaqueira do mato, Araçá baranhem, Pau bode, Louro sassafra, Pau sangue, Pau d'óleo, Imbiriariçu, Gameleira e Monzé. Esta vegetação proporciona uma serapilheira de aproximadamente $0,10 \mathrm{~m}$ de altura, cobrindo toda a superfície do solo.

\subsection{Gleba cultivada com citros}

A gleba vem sendo cultivada com citros desde a década de 70 (anteriormente cultivava-se pastagem) e dista aproximadamente $3 \mathrm{~km}$ da gleba sob mata. Atualmente se encontra cultivada com laranja Baía, num ensaio de competição de clones, no qual o porta-enxerto é o limão cravo. O laranjal está 
com 11 anos de idade e ocupa uma área de aproximadamente 3,0 ha, no espaçamento $7 \times 4 \mathrm{~m}$.

As recomendações de adubação e calagem tem seguido o manual de adubação e calagem para o Estado da Bahia, sendo o nitrogênio o elemento mais aplicado (COMISSÃO ESTADUAL DE FERTILIDADE DO SOLO, 1989).

O controle de ervas daninhas é feita mecanicamente com grade duas a três vezes durante o ano, a uma profundidade máxima de 0,05-0,10 $\mathrm{m}$ para não causar danos maiores às raízes.

A maior parte do sistema radicular dos citros se distribui principalmente de 0,40 a $0,60 \mathrm{~m}$ de profundidade, podendo aprofundar-se até cinco metros (Malavolta \& Violante Netto, 1989).

\subsection{Gleba cultivada com mandioca}

Nesta gleba cultiva-se um banco de germoplasma de mandioca, com 1660 variedades de todo o país. O plantio é em fileira dupla, e vem sendo cultivada nesta área desde 1975. No período de um ano e meio faz-se a colheita, plantando-se em uma outra área para preservação das espécies, ocupando uma área de 2,5 ha; dista $4.480 \mathrm{~m}$ da gleba sob mata.

As raízes da mandioca são tuberosas, fusiformes a cilíndricas - cônicas, medindo de 0,20 a $0,60 \mathrm{~m}$ de comprimento e 0,05 a $0,15 \mathrm{~m}$ de diâmetro, podendo atingir a profundidade de $1 \mathrm{~m}$ no solo. Já as raízes assimilarias, quase $100 \%$ estão a $0,30 \mathrm{~m}$ de profundidade.

\subsection{Coleta das amostras}

Em locais escolhidos ao acaso dentro da área de cada tratamento foram abertas dez trincheiras, para cada sistema de cultivo, para coleta das amostras de solo com estrutura indeformada, nas profundidades de 0,10 e $0,30 \mathrm{~m}$. No caso do citros, as trincheiras foram abertas sempre nas entrelinhas a 1,5 $\mathrm{m}$ do caule. No caso da mandioca utilizou-se o mesmo procedimento na entrelinha 
da fileira dupla, em pontos com plantas de porte semelhante. Foi coletada uma amostra por profundidade, totalizando 60 amostras indeformadas, visando a elaboração da curva de retenção da água e a determinação da densidade do solo. Nestas mesmas trincheiras, nas mesmas profundidades, foram coletados, aproximadamente, $0,3 \mathrm{~kg}$ de solo com estrutura deformada, para análise granulométrica e química.

\subsection{Determinações físicas}

\subsubsection{Granulometria e densidade das partículas ou massa específica dos sólidos}

Utilizou-se amostras de solo com estrutura deformada, após secas ao ar, desagregadas e passadas por peneira de malha de $2 \mathrm{~mm}$. As amostras foram utilizadas para obtenção da analise granulométrica e a obtenção da densidade dos sólidos, seguindo a metodologia de rotina do Laboratório de Física do Solo do Departamento de Ciências do Solo da ESALQ.

Na composição granulométrica, baseada na metodologia descrita em Gree \& Bauder (1986), $50 \mathrm{~g}$ de solo foram dispersas em solução aquosa de hexametafosfato de sódio puro $\left(6 \mathrm{~kg} \mathrm{~m}^{-3}\right)$ e hidróxido de sódio $\left(4 \mathrm{~kg} \mathrm{~m}^{-3}\right)$ por agitação durante dezesseis horas. A suspensão foi transferida para provetas com capacidade para $1000 \mathrm{ml}$, onde foram feitas duas leituras com densímetro de Bouyoucos. Na primeira leitura, realizada a $40 \mathrm{~s}$ após agitação manual para uniformização da suspensão, determinou-se a concentração de argila + silte. Duas horas após a agitação fez-se a segunda leitura, para determinação da concentração de argila. A concentração de silte foi determinada pela diferença entre a concentração inicial e a concentração de argila + silte obtida na primeira leitura.

Após as leituras, a areia foi separada da suspensão, por lavagem e peneiramento nas categorias muito grossa, grossa, média, fina e muito fina. 
A densidade de sólidos $\rho_{s}\left(\mathrm{~kg} \mathrm{~m}^{-3}\right)$, foi determinada pelo método do balão volumétrico, utilizando-se o álcool etílico para medição do volume de $20 \mathrm{~g}$ de solo, descrito por Kiehl (1979).

\subsubsection{Umidade, densidade, porosidade e curva de retenção}

Para determinação das curvas de retenção de água, foram utilizadas as amostras com estrutura indeformada. A amostragem foi feita utilizando um aparelho tipo "Uhland", com anéis volumétricos, de aproximadamente de 0,05 m altura, e 0,04 $\mathrm{m}$ de diâmetro. Cada amostra coletada foi utilizada para obtenção de cada um dos pontos da curva, que foi composta pelas tensões de $0,5,1,2,5,30,70,100,500$ e $1500 \mathrm{kPa}$. Como equipamentos foram utilizados funis de placa porosa para as tensões $0,5,1,2,5 \mathrm{kPa}$ e as câmaras de pressão com placa porosa para as tensões 30, 70, 100,500 e $1500 \mathrm{kPa}$. As amostras preparadas para elaboração das curvas de retenção foram colocadas em bandejas com água destilada e dearada, cujo nível era mantido por um gotejador de Mariotte, por um período de cerca de 24 horas. As amostras eram levadas com auxilio de um prato aos funis de placa porosa e às câmaras de pressão de Richards, onde eram submetidas as diferentes tensões. Após atingir o equilíbrio para cada tensão, tanto nos funis como nas câmaras de pressão na determinação das curvas de retenção, as amostras foram pesadas para determinação da sua massa úmida $(\mathrm{m}, \mathrm{kg}$ ). Após a aplicação da tensão de 1500 $\mathrm{kPa}$ as amostras foram secas em estufas a $105^{\circ} \mathrm{C}$, por 48 horas, para determinação da sua massa de sólidos ( $\mathrm{ms}, \mathrm{kg}$ ). Com estas informações foi feito o cálculo da umidade volumétrica $\left(\theta \mathrm{m}^{3} \mathrm{~m}^{-3}\right)$ e da densidade do solo $\left(\rho, \mathrm{kg} \mathrm{m}^{-3}\right)$ pelas equações :

$$
\rho=\frac{m s}{V} \quad \text { e } \quad \theta=\frac{(m-m s) \rho_{a}}{V}
$$


onde: $v=$ volume $\left(\mathrm{m}^{3}\right)$ do anel volumétrico de coleta e $\rho_{a}=$ densidade da água no solo $=1000 \mathrm{~kg} \mathrm{~m}^{-3}$.

Para as mesmas amostras de estrutura indeformada, utilizadas para a determinação das curvas de retenção, calculou-se a porosidade total, a partir da densidade do solo e da densidade dos sólidos, pela equação:

$$
P t=\left(1-\frac{\rho}{\rho_{s}}\right) \times 100
$$

onde:

$P t=$ porosidade total (\% em volume)

$\rho_{s}=$ densidade dos sólidos $\left(\mathrm{kg} \mathrm{m}^{-3}\right)$

$\rho=$ densidade do solo $\left(\mathrm{m}^{-3}\right)$

Com as tensões determinadas $\left(\theta ; \phi_{m}\right)$,obtiveram-se as médias referentes a $\theta$ para cada sistema em estudo e aplicou-se o teste de Tukey ao nível de significância de $5 \%$ visando efetuar a comparação entre os sistemas estudados.

Foi feito também o ajuste das curvas de retenção da água no solo à equação de Van Genuchten (1980), utilizou-se o programa desenvolvido por van Lier e Dourado Neto (1995). A equação de Van Genuchten considera o potencial mátrico $\phi \mathrm{m}$ como variável independente e a umidade volumétrica $\theta$ $\left(\mathrm{m}^{3} \mathrm{~m}^{-3}\right)$ como variável dependente e tem a seguinte forma:

$$
\theta=\theta_{r}+\frac{\theta_{s}-\theta_{r}}{\left[1+\left(\alpha \cdot\left|\phi_{m}\right|\right)^{n}\right]^{n}}
$$

onde:

$\theta_{r}=$ umidade volumétrica residual $\left(\mathrm{m}^{3} \mathrm{~m}^{-3}\right)$

$\theta_{s}=$ umidade volumétrica saturada $\left(\mathrm{m}^{3} \mathrm{~m}^{-3}\right)$ 
$\left|\phi_{m}\right|=$ módulo do potencial mátrico $(\mathrm{kPa})$

$\alpha\left(=\mathrm{kPa}^{-1}\right), m$ e $n=$ parâmetros empíricos da equação

No ajuste, $\theta_{r}, \theta_{s}, \alpha$ e $\mathrm{m}$ foram estimados por regressão e $n$ foi considerado função de $m$, isto é, $m=1-1 / n$.

Considerou-se como capacidade de campo a umidade do solo medida correspondente a tensão de $5 \mathrm{kPa}$ e como ponto de murchamento permanente a umidade do solo medida correspondente à tensāo de $1500 \mathrm{kPa}$. A capacidade de água disponível (CAD \%) foi determinada simplesmente pela diferença entre a capacidade de campo (\% em volume) e o ponto de murchamento permanente (\% em volume).

No Apêndice encontram-se os dados de granulometria e densidade dos sólidos e morfologia do solo de todo o perfil, obtidos em amostras coletadas das trincheiras abertas em cada um dos sistemas de uso (mata, citros e mandioca).

\subsection{Condutividade hidráulica relativa}

O parâmetro $m$ da equação de Van Genuchten (1980) pode ser utilizado para prever a condutividade hidráulica $K$ em função da umidade $\theta$, isto é, a função $K(\theta)$, pela seguinte expressão:

$$
K(\theta)=K_{o} \omega^{1 / 2}\left[1-\left(1-\omega^{1 / m}\right)^{m}\right]^{2}
$$

na qual $K_{0}$ é a condutividade hidráulica do solo saturado e $\omega$ é a saturação relativa do solo.

Por esta equação percebe-se que a razão $K(\theta) / K_{0}$, também chamada condutividade hidráulica relativa $\left(K_{r}\right)$, é tanto maior quanto maior for o $m$ para um mesmo $\omega$, com exceção dos extremos $\omega=0$ e $\omega=1$ para os quais ela vale zero e 1 , respectivamente, para qualquer valor de $m$. Desta maneira, a análise 
do parâmetro $m$ da curva de retenção pode dar uma boa idéia do comportamento da água em termos de sua condução no solo. 


\section{RESULTADOS E DISCUSSÃo}

\subsection{Curva de Retenção}

As tabelas 1, 2, e 3 apresentam os valores médios (10 repetições) das umidades e respectivos desvios padrões para cada tensão utilizada na determinação da curva de retenção da água no solo nas glebas sob mata, mandioca e citros, respectivamente. A partir dos dados dessas tabelas foram confeccionadas as seis curvas de retenção médias (mata: 0,10 e $0,30 \mathrm{~m}$; citros: 0,10 e 0,30 m e mandioca: 0,10 e 0,30 m) quais são representadas pelas Figuras 1 (mata), 2 (citros) e 3 (mandioca), devidamente ajustadas à equação de van Genuchten (1980). Analisando, visualmente, essas figuras observa-se que no caso da mata (Figura 1) as curvas às profundidades $0,10 \mathrm{~m}$ e $0,30 \mathrm{~m}$ só diferem entre si para valores de tensões menores que $10 \mathrm{kPa}$, isto é, muito próximo a saturação. $\mathrm{Na}$ área com mandioca (Figura 3) o comportamento é aproximadamente o mesmo. Já na área cultivada com citros (Figura 2) a diferença entre as curvas as profundidades de $0,10 \mathrm{~m} \mathrm{e} 0,30 \mathrm{~m}$ é mais perceptível para valores de tensão maiores que $10 \mathrm{kPa}$.

Tabela 1 - Umidade volumétrica média e respectivos desvios padrões para as diversas tensões da curva de retenção do solo sob mata às profundidades de 0,10 e $0,30 \mathrm{~m}$.

\begin{tabular}{|c|c|c|c|c|c|c|c|c|c|}
\hline \multirow{3}{*}{$\begin{array}{c}\text { Profundidad } \\
e \\
\text { (m) }\end{array}$} & \\
\hline & \multicolumn{9}{|c|}{$<-T e n s \tilde{e s}(\mathrm{kPa})$} \\
\hline & 0,5 & 1,0 & 2,0 & 5,0 & 30,0 & $\mathbf{7 0 , 0}$ & 100,0 & 500,0 & 1500,0 \\
\hline desvio & $\begin{array}{c}0,404 \\
(0,037)\end{array}$ & $\begin{array}{c}0,340 \\
(0,023)\end{array}$ & $\begin{array}{c}0.272 \\
(0.030)\end{array}$ & $\begin{array}{c}0,185 \\
(0,032)\end{array}$ & $\begin{array}{c}0,137 \\
(0,029)\end{array}$ & $\begin{array}{c}0.127 \\
(0,113)\end{array}$ & $\begin{array}{c}0,123 \\
(0,031)\end{array}$ & $\begin{array}{c}0,108 \\
(0,029 \\
)\end{array}$ & $\begin{array}{c}0,100 \\
(0.028)\end{array}$ \\
\hline desvio & $\begin{array}{l}0,377 \\
0,038\end{array}$ & $\begin{array}{l}0,330 \\
0.017\end{array}$ & $\begin{array}{l}0.279 \\
0.030\end{array}$ & $\begin{array}{l}0.201 \\
0.026\end{array}$ & $\begin{array}{l}0.143 \\
0.021\end{array}$ & $\begin{array}{l}0.134 \\
0.018\end{array}$ & $\begin{array}{l}0,120 \\
0.019\end{array}$ & $\begin{array}{l}0,108 \\
0,015\end{array}$ & $\begin{array}{l}0.096 \\
0.015\end{array}$ \\
\hline
\end{tabular}


Tabela 2 - Umidade volumétrica média e respectivos desvios padrões para as diversas tensões da curva de retenção do solo sob citros às profundidades de 0,10 e 0,30 m.

\begin{tabular}{ccccccccccc}
\hline \multirow{2}{*}{\begin{tabular}{c} 
Profundida $\begin{array}{c}\text { de } \\
(\boldsymbol{m})\end{array}$ \\
\cline { 3 - 11 }
\end{tabular}} & $\mathbf{0 ,}$ & $\mathbf{0 , 5}$ & $\mathbf{1 , 0}$ & $\mathbf{2 , 0}$ & $\mathbf{5 , 0}$ & $\mathbf{3 0 , 0}$ & $\mathbf{7 0 , 0}$ & $\mathbf{1 0 0 , 0}$ & $\mathbf{5 0 0 , 0}$ & $\mathbf{1 5 0 0 , 0}$ \\
\hline $\mathbf{0 , 1 0}$ & 0,3450 & 0,321 & 0,296 & 0,254 & 0,224 & 0,209 & 0,197 & 0,177 & 0,167 \\
& desvio & $(0,0173)$ & $(0,017)$ & $(0,014)$ & $(0,014)$ & $(0,017)$ & $(0,016)$ & $(0,017)$ & $(0,016)$ & $(0,016)$ \\
\hline $\mathbf{0 , 3 0}$ & & $\mathbf{0 , 3 4 3}$ & 0,311 & 0,282 & 0,239 & 0,203 & 0,193 & 0,177 & 0,159 & 0,148 \\
& desvio & $(0,016)$ & $(0,009)$ & $(0,014)$ & $(0,016)$ & $(0,019)$ & $(0,019)$ & $(0,019)$ & $(0,013)$ & $(0,012)$ \\
\hline
\end{tabular}

Tabela 3 - Umidade volumétrica média e respectivos desvios padrões para as diversas tensões da curva de retenção do solo sob mandioca às profundidades de 0,10 e 0,30 m.

\begin{tabular}{|c|c|c|c|c|c|c|c|c|c|}
\hline \multirow{2}{*}{$\begin{array}{c}\text { Profundida } \\
\text { de } \\
\text { (m) }\end{array}$} & \multicolumn{9}{|c|}{$\theta\left(m^{3} m^{-3}\right)$} \\
\hline & 0,5 & 1,0 & 2,0 & 5,0 & 30,0 & 70,0 & 100,0 & 500,0 & 1500,0 \\
\hline 0,10 & $\begin{array}{c}0,389 \\
(0,041)\end{array}$ & $\begin{array}{c}0,341 \\
(0,020)\end{array}$ & $\begin{array}{c}0,288 \\
(0,021)\end{array}$ & $\begin{array}{c}0,211 \\
(0,009)\end{array}$ & $\begin{array}{c}0,153 \\
(0,009)\end{array}$ & $\begin{array}{c}0,139 \\
(0,010)\end{array}$ & $\begin{array}{c}0,128 \\
(0,010)\end{array}$ & $\begin{array}{c}0,113 \\
(0,009)\end{array}$ & $\begin{array}{c}0,102 \\
(0,008)\end{array}$ \\
\hline desvio & $\begin{array}{c}0,357 \\
(0,036)\end{array}$ & $\begin{array}{c}0,322 \\
(0,013)\end{array}$ & $\begin{array}{c}0,288 \\
(0,018)\end{array}$ & $\begin{array}{c}0,227 \\
(0,016)\end{array}$ & $\begin{array}{c}0,168 \\
(0,019)\end{array}$ & $\begin{array}{c}0,157 \\
(0,020)\end{array}$ & $\begin{array}{c}0,143 \\
(0,143)\end{array}$ & $\begin{array}{c}0,126 \\
(0,125)\end{array}$ & $\begin{array}{c}0,116 \\
(0,016)\end{array}$ \\
\hline
\end{tabular}

A fim de se ter um critério estatisticamente confiável, aplicou-se o teste de Tukey para cada tensão utilizada $(0 ; 0,5 ; 1,0 ; 2,0 ; 5,0 ; 30,0 ; 70,0 ; 100,0$; 500,0 e $1500,0 \mathrm{kPa}$ ) às médias dos seis tratamentos (citros a $0,10 \mathrm{~m}$ de profundidade ou citros 10; citros a $30 \mathrm{~m}$ de profundidade ou citros a 30; mandioca a $0,10 \mathrm{~m}$ de profundidade ou mandioca 10 ; mandioca a $0,30 \mathrm{~m}$ de profundidade ou mandioca 30 ; mata a $0,10 \mathrm{~m}$ de profundidade ou mata $10 \mathrm{e}$ mata a $0,30 \mathrm{~m}$ de profundidade ou mata 30 ), cujos resultados encontram-se dispostos na Tabela 4.

Por esta Tabela 4, portanto, que mostra se um tratamento difere ou não estastiscamente $(\mathrm{P}<0,05)$ de outro, algumas informaçōes relevantes podem ser obtidas e discutidas. Considerando, separadamente, o citros, a mandioca e a mata, verifica-se que não há diferença significativa de porosidade total entre as 
profundidades $0,10 \mathrm{~m}$ e 0,30 $\mathrm{m}$. Considerando a mesma profundidade, observase que, a $0,10 \mathrm{~m}$ de profundidade, a porosidade total do tratamento mata 0,10 $\mathrm{m}$ é igual ao mandioca $0,10 \mathrm{~m}$ mas difere do citros $0,10 \mathrm{~m}$. Isto é, considerando a mata como referência, pode-se dizer que o tipo de manejo do citros diminuiu a porosidade do solo, enquanto que no caso da mandioca isto não aconteceu, isto é, o manejo utilizado no cultivo da mandioca, aparentemente, não afetou, significativamente a porosidade do solo a $0,10 \mathrm{~m}$ de profundidade. Nesta profundidade $(0,10 \mathrm{~m})$ a classe textural do solo é a mesma tanto na mata como no citros quanto na mandioca (Tabela 5). Considerando que na profundidade de $0,30 \mathrm{~m}$ não há diferença significativamente da porosidade total entre os três cultivos (mata, citros e mandioca) apesar da diferença de granulometria, notadamente no caso do tratamento mata $0,30 \mathrm{~m}$ (Tabela 5). Esta análise que se acabou de fazer com relação à porosidade total ou umidade à tensão de $0 \mathrm{kPa}$ é a mesma para umidades correspondentes à tensão de $0,5 \mathrm{kPa}$, para ambas as profundidades, mostrando que para a tensão de $0,5 \mathrm{kPa}$ o comportamento da retenção de água para os tratamentos em questão não mudou, considerando-se evidentemente, as análises por profundidade e por cultivos.

Na tensão de 1,0 e $2 \mathrm{kPa}$ de água, há uma maior uniformização dos tratamentos, isto é, a essa tensão não há diferença significativa para as duas profundidades de um mesmo cultivo e nem diferença significativa de umidade entre cultivos para ambas as profundidades. Portanto, o manejo e o uso do solo parece não ter afetado a retenção da água à tensão de 1,0 e $2,0 \mathrm{kPa}$. Os resultados de umidade à tensão de $2,0 \mathrm{kPa}$, mostram que a essa tensão os valores de umidade são todos estatisticamente iguais, o que é bem visualizado no gráfico da Figura 4 pelo qual percebe-se que na vizinhança dessa tensão, na realidade um valor um pouco menor que $0,20 \mathrm{~m}$ de água, praticamente todas as linhas das curvas de retenção dos seis tratamentos se cruzam.

A partir da tensão de $5 \mathrm{kPa}$ até a tensão de $1500 \mathrm{kPa}$, o comportamento da retenção da água foi estatisticamente o mesmo entre os tratamentos, isto é, 
em relação à mata, para todas as tensões estudadas iguais ou maiores que 5 $\mathrm{kPa}$, à semelhança do que ocorreu com as tensões 0 e $5 \mathrm{kPa}$, tanto para profundidades de $0,10 \mathrm{~m}$, como para a profundidade de $0,30 \mathrm{~m}$, o citros diferiu da mata mas a mandioca não. Ou seja, as umidades correspondentes às tensões maiores ou igual a $5 \mathrm{kPa}$ foram sempre estatisticamente maiores no citros do que na mata (observe que no caso das tensões 0 e $0,5 \mathrm{kPa}$, a umidade na mata foi maior), o mesmo não ocorrendo, com a mandioca, para a qual as umidades foram estatisticamente iguais ao da mata. Estes resultados mostram claramente que no citros o manejo compactou o solo de maneira muito mais intensa do que na mandioca, como se pode ver pelos dados de densidade do solo na Tabela 5, fazendo com que o solo no sistema de uso e manejo com citros retenha menos água que a mata a baixas tensões e mais água que a mata a altas tensões. No caso da mandioca, apesar de também ter compactado o solo (Tabela 5), o processo foi menos intenso e não chegou a afetar a retenção da água. 


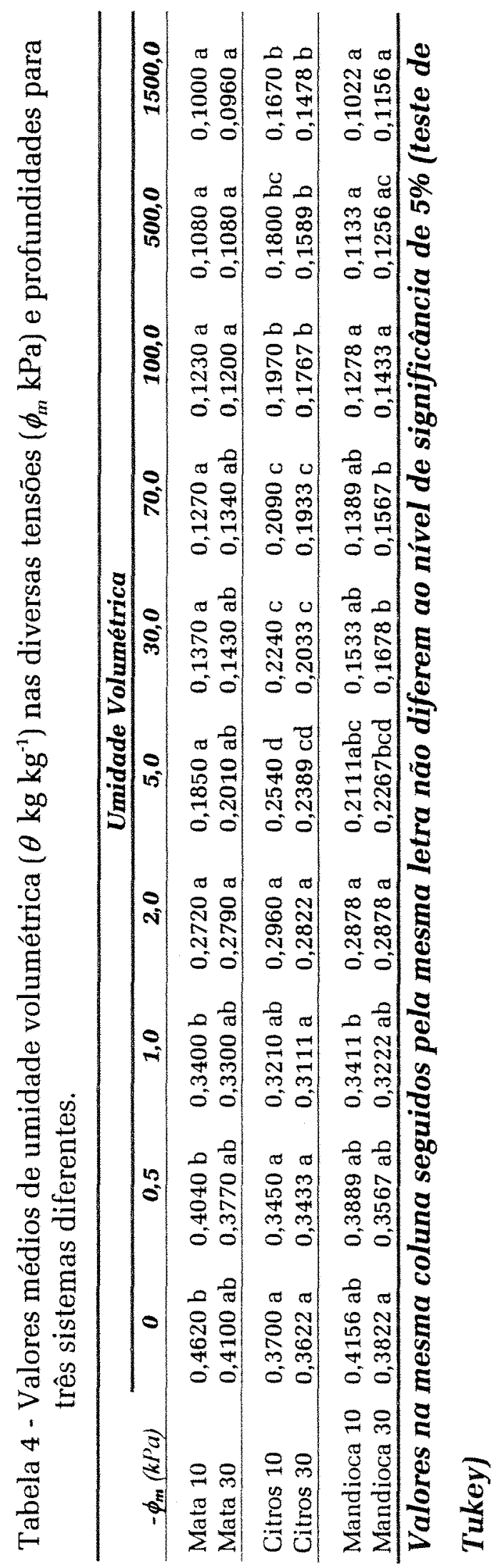




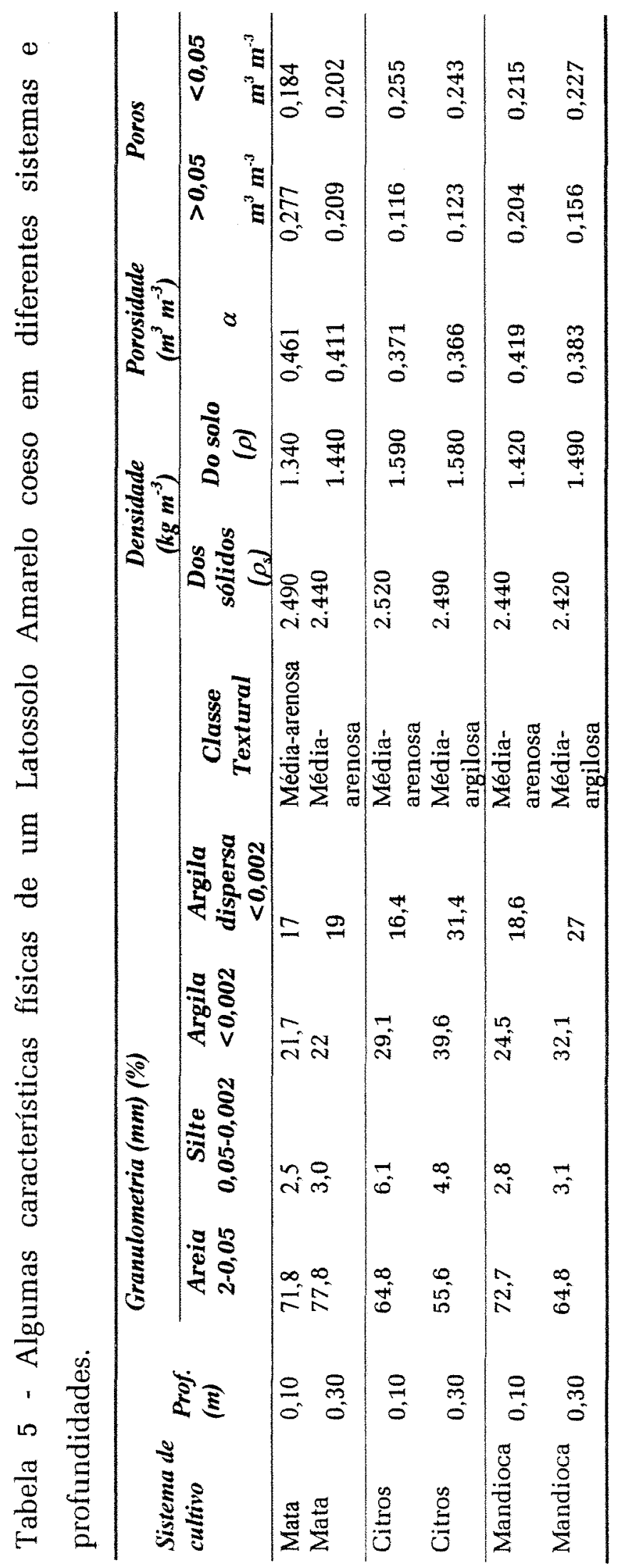


Ainda com relação a curva de retenção, os dados da Tabela 4 revelam que para valores de tensão maiores ou igual a tensão de $5 \mathrm{kPa}$ para ambas as profundidades, com a única exceção da profundidade $0,30 \mathrm{~m}$ à tensão de $5 \mathrm{kPa}$, os valores de umidade, comparando citros com mandioca, foram estatisticamente diferentes, com os do citros sempre maiores que os da mandioca, o que comprova nossa hipótese.

\subsection{Capacidade de água disponível}

Considerando a capacidade de campo como a umidade correspondente à tensão de $5 \mathrm{kPa}$, a qual podemos considerar como um valor razoável para o solo em questão (teor de areia maior que $0,50 \mathrm{~kg} \mathrm{~kg}^{-1}$ ), e o ponto de murchamento permanente como a umidade correspondente à tensão de 1500 $\mathrm{kPa}$, calculou-se a capacidade de água disponível a partir dos dados das Tabelas 1, 2 e 3 e aplicou-se o teste de Tukey ao nível de significância de $5 \%$ de probabilidade. Os resultados obtidos são os listados a seguir, na Tabela 6, para cada tratamento.

Tabela 6 - Capacidade de água disponível para as profundidades e tratamentos avaliados.

\begin{tabular}{ccc}
\hline Tratamento & Profundidade & $\begin{array}{c}\text { Capacidade de água } \\
\text { disponível }\end{array}$ \\
\hline Mata & $(\mathrm{m})$ & $\left(\mathrm{m}^{3} \mathrm{~m}^{-3}\right)$ \\
Mata & 0,10 & $0,085 \mathrm{bc}$ \\
Citros & 0,30 & $0,105 \mathrm{bc}$ \\
Citros & 0,10 & $0,087 \mathrm{ab}$ \\
Mandioca & 0,30 & $0,091 \mathrm{abc}$ \\
Mandioca & 0,10 & $0,109 \mathrm{c}$ \\
\hline
\end{tabular}

Valores seguidos pela mesma letra não diferem entre si ao nível de significância de $5 \%$ pelo teste de Tukey.

Em relação a capacidade de água disponível (CAD), verifica-se que, a $0,30 \mathrm{~m}$ de profundidade, não há diferença estatística entre Mata e Citros, Mata 
e Mandioca, nem entre Citros e Mandioca. Nesta profundidade o uso e manejo do solo com citros ou mandioca não afetou a CAD em relação a mata. A $0,10 \mathrm{~m}$ de profundidade, entretanto, houve mudança na disponibilidade de água pelo solo, isto é, a CAD do tratamento com mandioca foi estatisticamente maior do que a $\mathrm{CAD}$ do tratamento com citros, apesar de que, em relação à mata, não ter havido diferença da CAD nem da mandioca nem do citros.

\subsection{Condutividade hidráulica relativa}

Os dados a seguir (Tabela 7) mostram os valores de $m$ resultantes do ajuste dos dados das tabelas 1, 2 e 3 à equação de Van Genuchten (1980), já com a aplicação do teste de Tukey ao nível de significância de $5 \%$ de probabilidade.

Tabela 7 -Valores de $m$ resultantes do ajuste dos dados da tabela 2 à equação de Van Genuchten (1980) para as profundidades e tratamentos avaliados.

\begin{tabular}{ccc}
\hline Tratamento & Profundidade & m \\
\hline & $(\mathrm{m})$ & \\
Mata & 0,10 & $0,4254 \mathrm{C}$ \\
Mata & 0,30 & $0,3966 \mathrm{C}$ \\
Citros & 0,10 & $0,2069 \mathrm{a}$ \\
Citros & 0,30 & $0,2491 \mathrm{ab}$ \\
Mandioca & 0,10 & $0,3943 \mathrm{C}$ \\
Mandioca & 0,30 & $0,3262 \mathrm{bc}$ \\
\hline
\end{tabular}

"Valores seguidos pela mesma letra não diferem entre si ao nível de significância de $5 \%$ pelo teste de Tukey.

Por estes dados percebe-se que, para a profundidade de $0,10 \mathrm{~m}$, o valor de $m$ do solo da mata é, estatisticamente, maior do que o do solo do citros. No caso da mandioca, entretanto, o valor de $m$ do solo, a profundidade de $0,10 \mathrm{~m}$, não difere estatisticamente do valor da mata. Com isso pode-se inferir que, em termos de condutividade hidráulica relativa, o cultivo da mandioca não interferiu, estatisticamente, no seu valor com relação a mata na profundidade de $0,10 \mathrm{~m}$, mas que o cultivo de citros, ao contrário, diminuiu o valor dessa 
propriedade. $\mathrm{O}$ mesmo fenômeno aconteceu à profundidade de $0,30 \mathrm{~m}$ só que, neste caso, ao contrário do anterior (profundidade de $0,10 \mathrm{~m}$ ) também não houve diferença estatística entre os valores de $m$ do citros e da mandioca. Portanto, conforme se diminui a umidade do solo, a condutividade hidráulica do solo sob o citros é reduzida mais rapidamente do que a do solo sob a mata, o mesmo não ocorrendo com o solo sob a mandioca que se comportou identicamente ao solo sob a mata (Figura 5).

Para se calcular o valor de $K(\theta)$, além do valor de $K_{r}$ deve se conhecer o valor de o $K$, que não foi determinado nesse estudo. Porém, é sabido que $K_{o}$ tem uma alta correlação com a porosidade total do solo e com a sua macroporosidade; ambas menores para o solo sob citros. Consequentemente, esse solo apresentará valores de $K(\theta)$ sempre inferiores aos dos outros tratamentos.

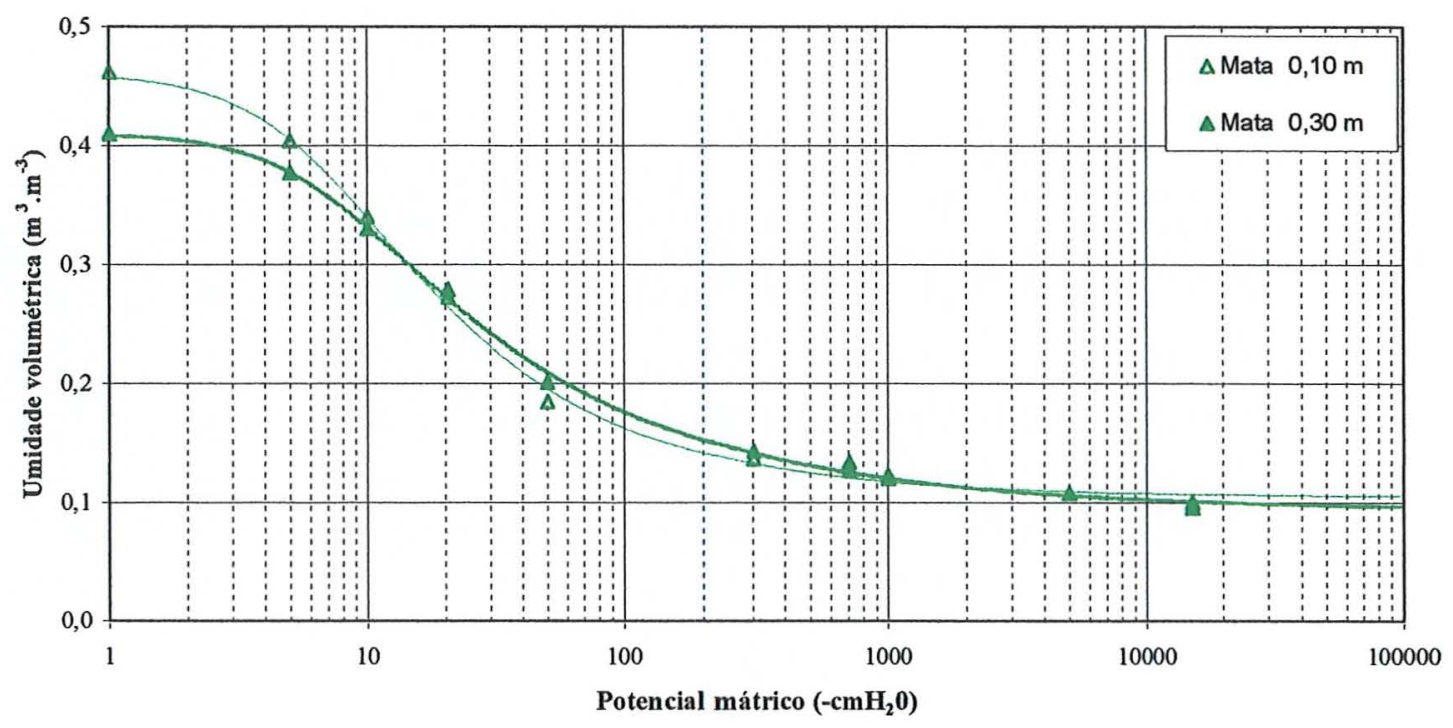

Figura 1 - Curvas de retenção de água num Latossolo Amarelo coeso com vegetação natural (mata), em duas profundidades. 


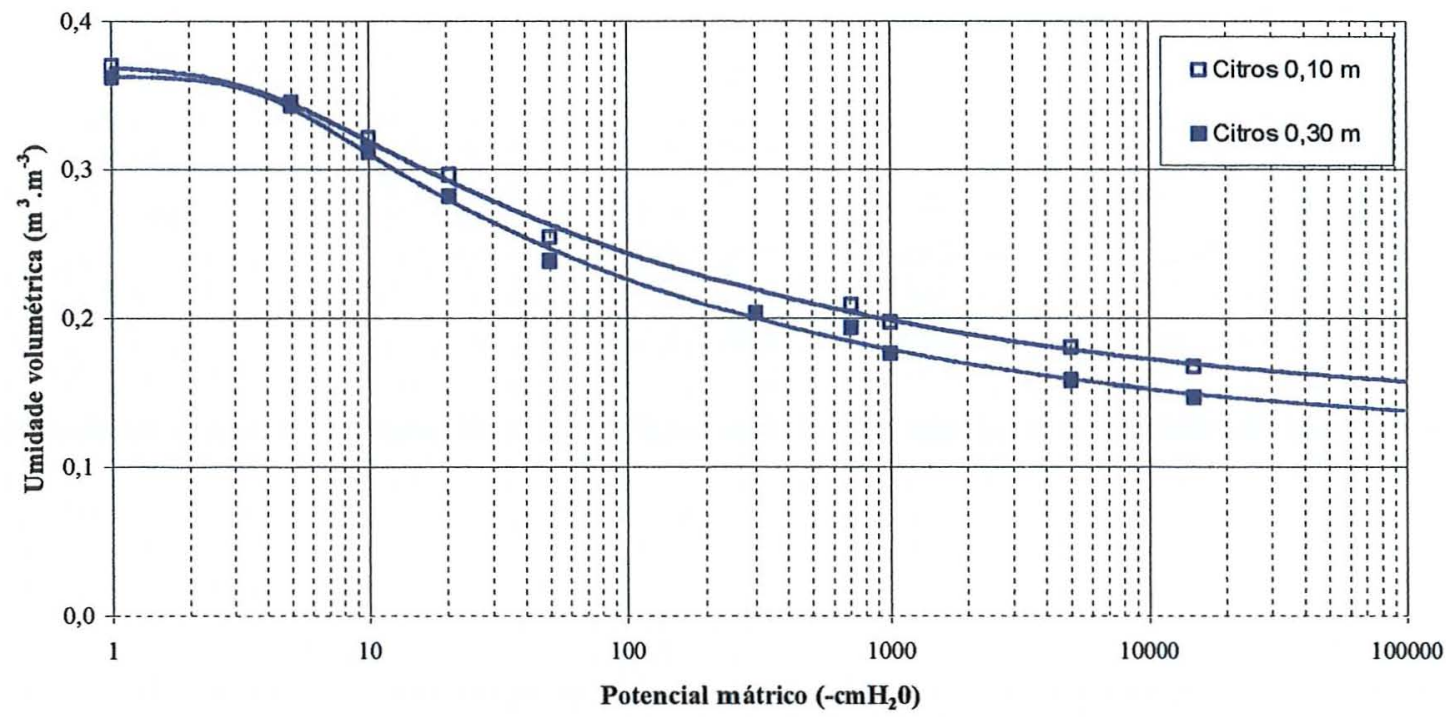

Figura 2 - Curvas de retenção da água num Latossolo Amarelo coeso, para a cultura do citros em duas profundidades.

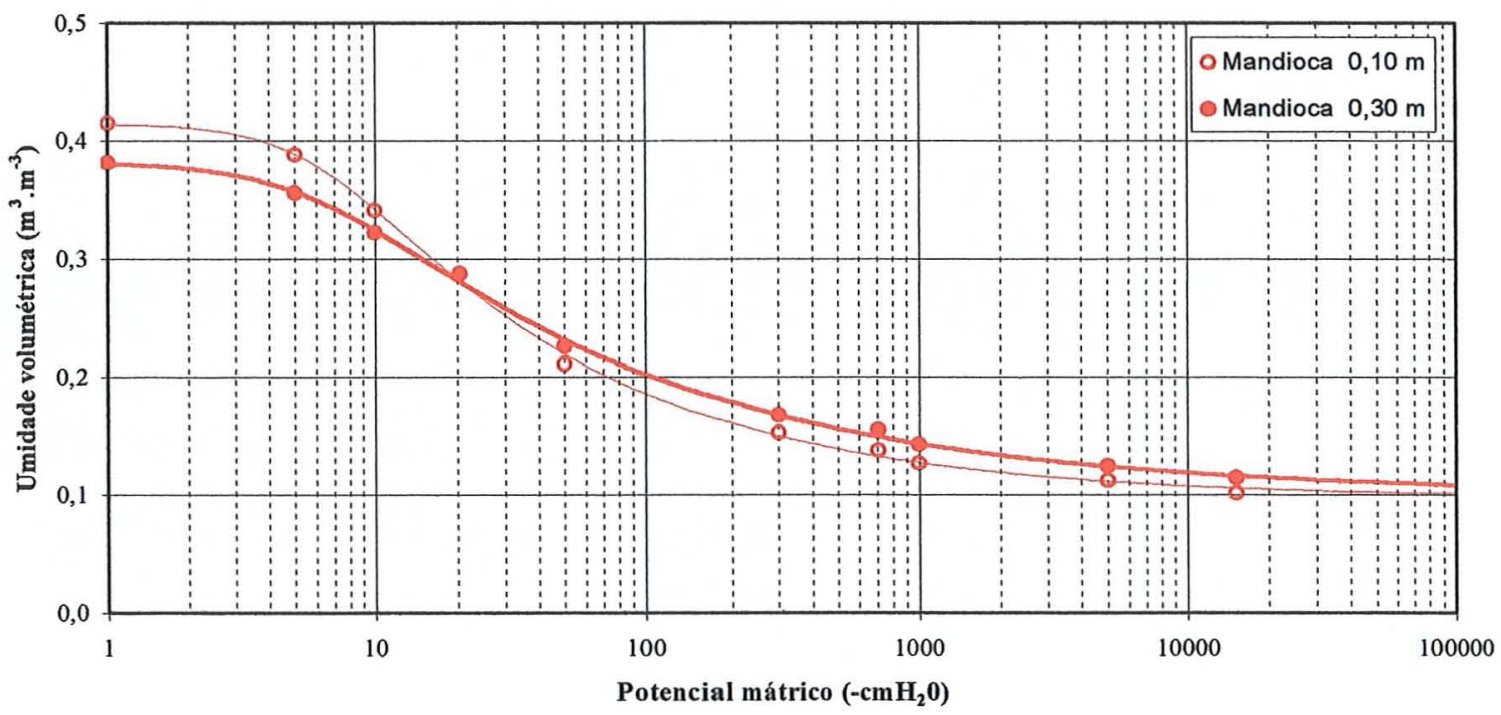

Figura 3 --Curvas de retenção de água no solo num Latossolo Amarelo coeso, para a cultura da mandioca em duas profundidades. 


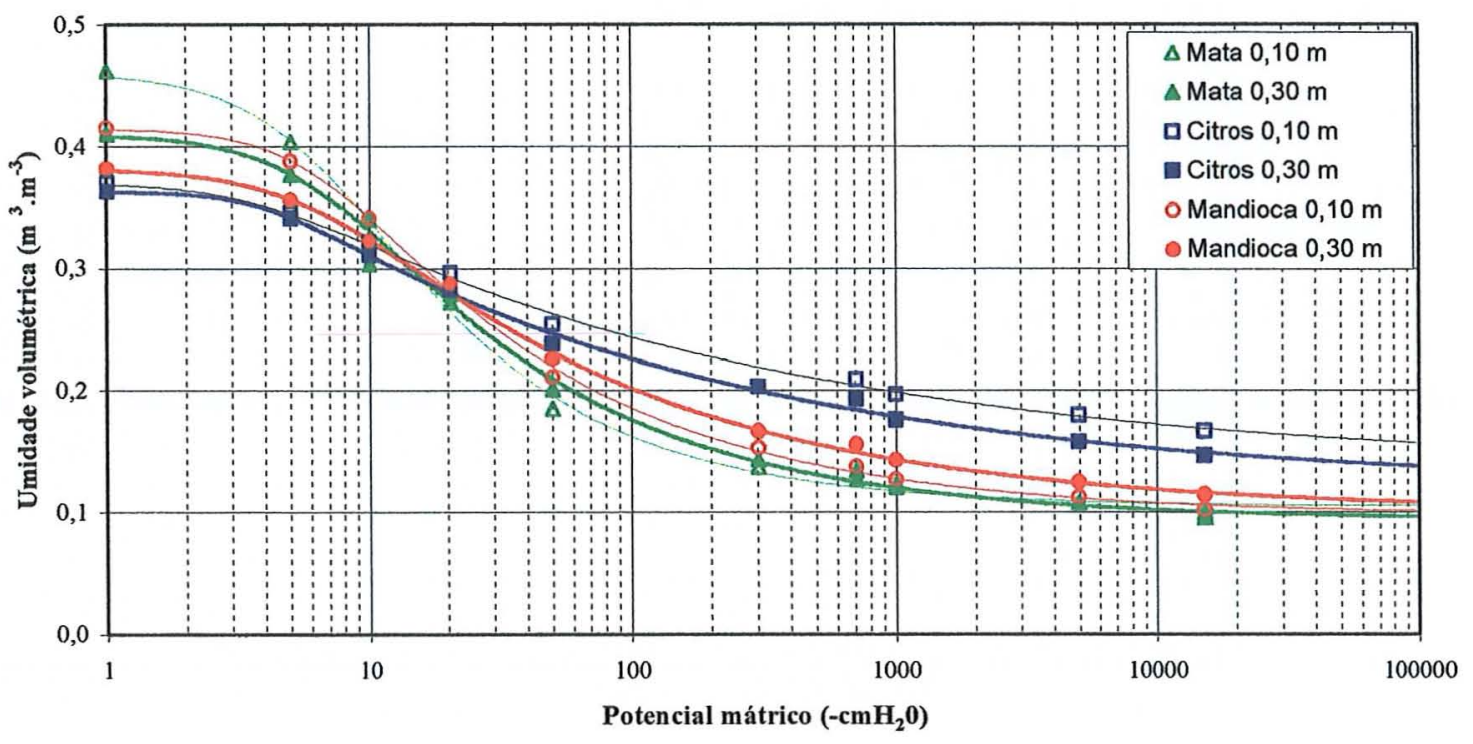

Figura 4-Curvas de retenção da água num Latossolo Amarelo coeso, para diferentes sistemas e profundidades.

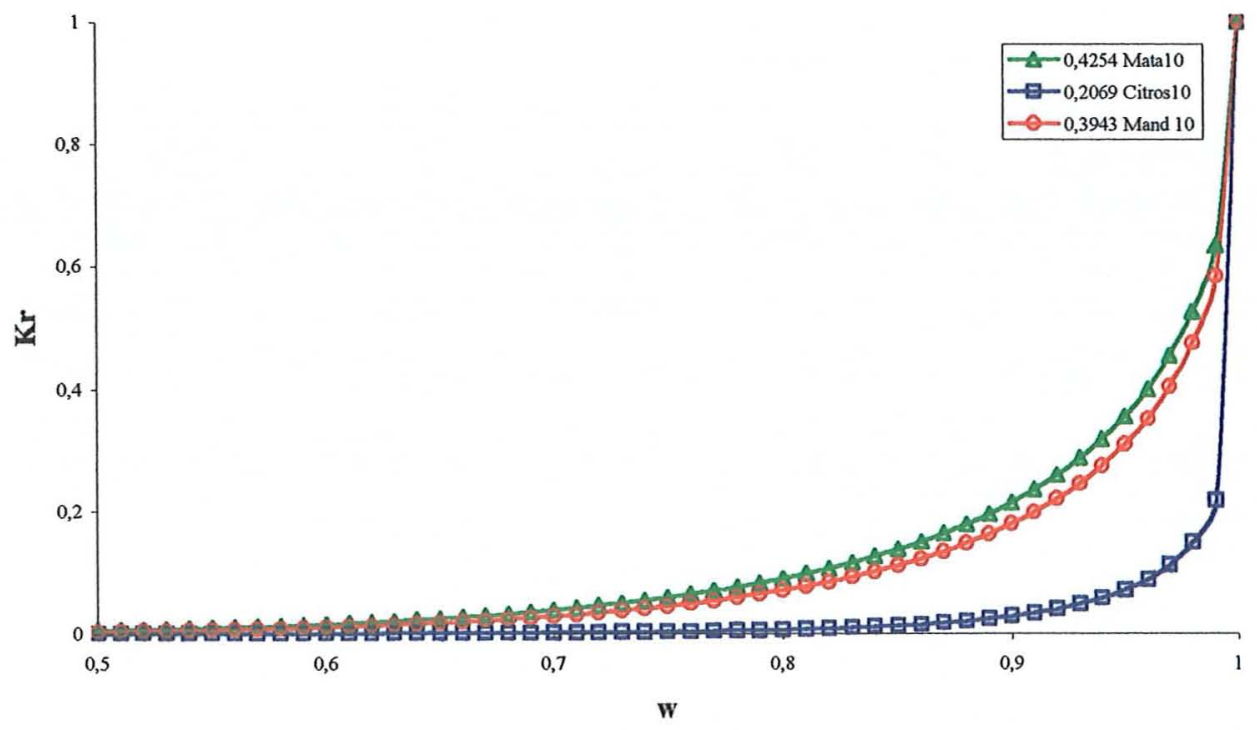

Figura 5 - Condutividade hidráulica relativa em função da saturação relativa efetiva do solo para os três tratamentos à profundidade de $0,10 \mathrm{~m}$ (Mata 10, Citros $10 \mathrm{e}$ Mandioca 10). 


\section{CONCLUSÕES}

Com o manejo e o cultivo na cultura do citros, ocorreu uma tendência de aumento na densidade do solo na camada superficial, retendo menos água que a mata a baixas tensões e mais que a mata a altas tensões indicando que a perda de porosidade devem-se à redução da macroporosidade. Observou-se que o aumento da densidade do solo proporcionou menor quantidade de água disponível nos sistemas em estudo, logo tem efeito do manejo além da expressão genética da camada coesa.

Tensōes maiores ou igual a $5 \mathrm{kPa}$ de água para ambas as profundidades, com a única exceção da profundidade $0,30 \mathrm{~m}$ à tensão de $5 \mathrm{kPa}$ de água, os valores de umidade, comparando citros com mandioca, foram estatisticamente diferentes, com os citros sempre maiores que os da mandioca.

As curvas de retenção, na mata às profundidades de 0,10 e $0,30 \mathrm{~m}$ só diferem entre si para os valores de tensões menores que $1 \mathrm{kPa}$, isto é, muito próximo a saturação, em que citros difere da mata e mata não difere de mandioca; para o citros as diferença entre as curvas é mais perceptível para valores de tensão maiores que $1 \mathrm{kPa}$.

Não houve diferença estatística $(\mathrm{P}>0,05)$ entre os tratamentos mata, citros e mandioca em relação a porosidade total entre as profundidades $0,10 \mathrm{e}$ $0,30 \mathrm{~m}$, sendo que a mata e mandioca a $1 \mathrm{kPa}$ m são iguais e diferiu do citros. Acredita-se que os tratos culturais utilizados na cultura do citros diminuiu a porosidade do solo. 
$\mathrm{O}$ uso do solo com mandioca aumentou a capacidade de água disponível do solo a $0,10 \mathrm{~m}$ de profundidade em relação ao citros.

Com relação a condução de água é muito provável que o solo com citros apresente valores de condutividade hidráulica sempre inferiores que os da mata e mandioca, com resultado de sua macroporosidade e condutividade relativa. 


\section{REFERÊNCIAS BIBLIOGRÁFICAS}

AGUIAR NETO, O.; NACIF, P.G.S. Caracterização morfológica e físico-hídrica de solos representativos do Recôncavo Baiano. Determinação da capacidade de campo "in situ" e suas relações com dados obtidos em laboratório. Cruz das Almas, 1988. 58p. Escola de Agronomia - Universidade Federal da Bahia.

AINA, P.O. Soil changes resulting from long - term management practices in Western Nigeria. Soil Science Society of American Journal, Madison, v.43, n.1: p.173-177. 1979.

ALHEIROS, M.M; LIMA FILHO, M.F. de; MONTEIRO, F. de Sistemas deposicionais na formação barreiras no Nordeste Oriental. In: Congresso Brasileiro de Geologia 35, Anais, v.2. Belém, 1988. p.753-760.

ALMEIDA, F.F.M. Os fundamentos geológicos. In: AZEVEDO, A. Brasil a terra e o homem. São Paulo: Cia. Ed. Nacional, 1964. 607p.

AYOADE, J.O. Introdução à climatologia para trópicos. Rio de Janeiro: 4. ed Bertrand. Brasil, 1996. 489p.

BAVER, L.D. Soil Physics 3 ed. New York: John Willey and Sons, 1966.489p.

BRADY, N.C. Natureza e propriedades dos solos. Trad. de A. B. Neiva de Figueiredo Filho. 7 ed., Livraria Freitas Bastos S/A. 1989. 878p.

BRASIL. Ministério da Agricultura. Levantamento exploratório reconhecimento de solos do Espírito Santo. Rio de Janeiro, 1976. (Boletim Técnico, 36). 
BRASIL. Ministério das Minas e Energia. Projeto Radambrasil. Folhas SC 24/25 Aracaju/ Recife: geomorfologia, pedologia, vegetação e uso potencial da terra. Rio de Janeiro, 856 p. v.3, 1983.

CARMO, G.F. do Balanço hídrico do Município de Cruz das Almas para a cultura da mandioca (Manihot esculenta Crantz), segundo Thornthwaite \& Mather-1995. Projeto mandioca, série pesquisa, v.1, n.1, p.61-77. 1973.

CASSEL, D. K. \& NIELSEN, D. R. Field capacity and avalilable water capacity. In : Methods of soil analysis. Parte I. Phisical and mineralogical methods. Madison, American Society of Agronomy, Soil Science Society of America, 1986. p 901-926.

CINTRA, F.L.D. Disponibilidade de água no solo para porta-enxertos de citros em ecossistema de tabuleiro costeiro. Tese (doutorado) - ESALQ/USP, 1997, 90p.

CINTRA, F.L.D.; COELHO, Y.S. Caracterização física do solo em pomares da região citrícola do Recôncavo Baiano. Revista Brasileira de Fruticultura, Cruz das Almas, 1987, v.9, n.1, p.27 -35.

CINTRA, F.L.D.; COELHO, Y.S.; CUNHA SOBRINHO, A.P. da; PASSOS, O.S. Caracterização física do solo submetido a práticas de manejo em pomar de laranja Baianinha. Pesquisa Agropecuária Brasileira, Brasília, v.18, n.2, p.173-179. 1983.

CINTRA, F.L.D.; CUNHA, G.A.P. da. Caracterização Física de Solos cultivados com abacaxi em áreas com diferentes tempos de utilização. Revista Brasileira de Fruticultura, Cruz das Almas, 1987, v.9, n.3, p.7-15.

CINTRA, F.L.D.; LIBARDI. P.L.; SILVA, A.P. Tabuleiros Costeiros do Nordeste do Brasil: Uma análise dos efeitos do regime hídrico e da presença de camadas coesas nos solos. Campinas, SP. Sociedade Brasileira de Ciência do Solo, v.22, p.77-80. 1997. (Boletím Informativo, 2). 
COELHO, R.M. Influência da vinhaça, da fertilização mineral e do cultivo em características químicas da matéria orgânica e da fração mineral de um Latossolo Vermelho Escuro. Viçosa, 1990. 84p. (Mestrado - Universidade Federal de Viçosa).

COMISSÃO ESTADUAL DE FERTILIDADE DO SOLO. Manual de adubação e calagem para o Estado da Bahia. Salvador, CEPLAC/ EMATER/ EMBRAPA/ EPABA/ NITROFÉRTIL, 1989. 176p.

COOTE, D.R.; RAMSEY, J.F. Quantification of the effects of overs 35 years of intensive cultivation on four soils. Canadian Journal of Science, Ottawa, v.63, n.1, p.1-14, 1983.

CUNNINGHAM, R.K. The effect of clearing a tropical forest soil . Journal of Soil Science, Oxford, v.14, n.2, p.334-345, 1963.

DEMATTÊ, J.L.I. Charateristics of brasilian soils related to root growth. In: Russel, R. S, Igue ,K \& Mehta, Y.R (eds) The soil/root system in relation to brazilian agriculture. Londrina, PR. Fundação Instituto Agronômico do Paraná. p.21-41. 1981.

EMPRESA BRASILEIRA DE PESQUISA AGROPECUÁRIA. Centro Nacional de Pesquisa de Solos. Sistema Brasileiro de Classificação de Solos. Brasília: EMBRAPA. Produções de Formações; Rio de Janeiro, EMBRAPA Solos, 1999. 412p.

EMPRESA BRASILEIRA DE PESQUTSA AGROPECUÁRIA. Centro Nacional de Pesquisa de Mandioca e Fruticultura Tropical. Relatório Técnico Anual, Cruz das Almas, 1991. 196p.

EMPRESA BRASILEIRA DE PESQUISA AGROPECUÁRIA. Superintendência de Desenvolvimento do Nordeste. Levantamento exploratórioreconhecimento de solos do Estado de Sergipe. Recife: EMBRAPA, Centro de Pesquisa Pedológicas. 1975, 506p.(Boletim Técnico, 36). 
FIALHO, J.F. Efeito da cobertura vegetal sobre características físicas e químicas e atividade da microbiota de um Latossolo Vermelho - amarelo distrófico, na região de Viçosa - MG, 1985. 55p. (Mestrado Universidade Federal de Viçosa).

FONSECA, O.O.M. Caracterização e classificação de solos latossólicos e podzólicos desenvolvidos de sedimentos do Terciário no Litoral Brasileiro. Tese de Mestrado. Universidade Federal Rural do Rio de Janeiro, Itaguaí, RJ, $1986,185 p$.

FORSYTHE, W. Física de Suelos. San José: Costa Rica. IICA. 1975. 212p.

FOURY, A.P. As matas do Nordeste brasileiro e sua importância econômica. SUDENE B. Recursos Naturais, v.4, n.2, p.123-124. 1966.

FREITAS, P.L. de; BLANCANEAUX, P. Metodologia de pesquisa em manejo do solo: Estrutura e porosidade do solo. In: Reunião sobre metodologia de pesquisa em manejo do solo, v.2; 28p. 1990.

GODEFROY, J.; JACQUIN, F. Relation entre la stabilité structurale des sols cultivés et les apports organiques en conditions tropicales; comparasion avec les sols forestiers. Fruits, Paris, v.30, n.10, p.595 -612, 1975.

GREE, G.W.; BAUDER, J.C. Partile size analysis. In: KLUTE, A. (Ed.) Methods of soil analysis: physical and mineralogical methods. 2 ed. Madison: American Science Society of America, 1986. cap.15, p.383-411.

GROWMANN, F. Compacidade. In: A. C. Moniz, São Paulo, SP. Elmentos de Pedologia, cap.8, p.93-84. 1972.

HILLEL, D Introduction to Soil Physics. New York, Academic Press, 1982. 365 p.

HILLEL, D. Solo e água; fenômenos e princípios físicos. Porto Alegre RS: UFRGS, 231p. 1970. 
JACOMINE, P.K.T. Distribuição geográfica, características e classificação dos solos coesos dos tabuleiros costeiros. Pesquisa e Desenvolvimento para os tabuleiros costeiros, Aracaju, SE. EMBRAPA-CPATC/CPMF, EAUFBA; IGUFBA, 80p. 1996.

JACOMINE, P.K.T. Fragipans em solos de tabuleiros; Caracterização, gênese e implicações no uso agrícola. Recife, PE, 1974, 83p. Tese de livre docente. Universidade Federal de Pernambuco.

JUO, A.S.R.; LAL, R. The effect of fallow and continous cultivation on the chemical and physical properties of an Alfisol in Western Nigéria. Plant and Soil, Dordrecht, v.47, n.3, p.567 - 584. 1977.

KERN, J.S.; Geographic Patterns of Soil Water - Holding Capacity in the Contiguous United States. Soil Science Society American Journal. v.59, p.1134-1141. 1995.

KIEHL, E. J. Manual de Edafologia. São Paulo, SP: Ceres 1979. 262p.

LEÃO, A.C.; MELO, A.O. Características morfológicas, físico-químicas e mineralógica dos solos da estação ecológica de Pau-Brasil. Porto Seguro, BA. Agrotrópica: v.2., n.2, p.2. 1990.

LETEY, J. Relationship between soil physical properties and crop productions. Advances in Soil Science, v.1, p.277-294. 1985.

LIBARDI, P.L. Dinâmica da Água no Solo. Editado pelo Autor. ESALQ/USP, 1995, 497p.

LIER, Q.J. van; DOURADO NETO, D. Curvaret. Programa para confeç̧ão da curva de retenção de água no solo utilizando o modelo de van Genuchten. Departamento de Física e Meteorologia/Agricultura, versão 2.16, 1991-95.

MACHADO, J.A.; SOUZA, D.M. de; BRUM, A.C.R. de. Efeito de anos de cultivo convencional em propriedades físicas do solo. Revista Brasileira de Ciência do Solo, Campinas, v.5, n.3, p.187-189. 1981. 
MAIA, J.C.S. Influencia de tipo de preparo do solo sobre algumas características físicas e comportamento radicular da cultura da soja (Glicine max, L.) em um solo sob vegetação de cerrado. CD ROM dos Anais do XIII Congresso Latino Americano de Ciência do solo. Águas de Lindóia, SP. Sociedade Brasileira de Ciência do Solo, 1996.

MALAVOLTA, E; VIOLANTE NETTO, A. Nutrição mineral, calagem, gessagem e adubação dos citros. Piracicaba, SP: POTAFOS, 1989, 83p.

MATOSO, S.Q.M.; ROBERTSON, F.S. Uso geológico do termo "barreiras". Boletim Técnico da Petrobrás. v.2, n. 3. Rio de Janeiro. 1959. p.12-26.

MELO FILHO, H.R.F. de; ARÁUJO FILHO, J.C. de. Descrição perfil da mata de Cruz das Almas. Recife. EMBRAPA/ Serviço Nacional de Levantamento e Conservação do Solo - Nordeste, 1984. 4p.

MONIZ, A.C. Evolução de conceitos no estudo da gênese de solos. Revista Brasileira de Ciências do Solo, v.20, n.3, p.349 -362, 1996.

MORAES, S.O.; LIBARDI, P.L.; Dourado Neto, D. Problemas metodológicos na obtenção da curva de retenção da água pelo solo. Scientia Agricola, v.50, Piracicaba, p.383-392, 1993.

MOTA, P.P. Variação do potencial total da água em um Latossolo amarelo álico coeso, ao longo do tempo e em diferentes sistemas de preparo. Cruz das Almas, BA: UFBA/Escola de Agronomia, 1995. 62p. (Dissertação de Mestrado).

NEVES, A.D.S.; LIMA, F.A M.; MOREIRA, E.G.S. Efeito de coberturas vegetais sobre propriedades físicas de Latossolo Amarelo (Pará). In: Congresso Brasileiro de Ciência do Solo, v.23, Porto Alegre. Resumo. Sociedade Brasileira de Ciência de Ciência do Solo/UFRGS, 1991. p.169. 
OLIVEIRA, J.B. de. O estudo físico do solo e a aplicação racional de técnicas conservacionistas. Pesquisa Agropecuária Brasileira, Rio de Janeiro, v.2, p.281-285. 1967.

OLIVEIRA, J.B. de; DANTAS, H.S. da; CAMPELO, A.B.; GALVÃO, S.J.; GOMES, I.F. Caracterização de adensamento no subsolo de uma área de tabuleiro da Estação Experimental de Curado, Recife. Pesquisa Agropecuária Brasileira, Rio de janeiro, v.3, p.207-214, 1968.

PACHECO, E.B.; SILVA, T.C.A.; SANTOS, H.L. dos; FELDMANN, R.O.; TEIXEIRA, S.L. Efeito do manejo de um Latossolo Vermelo Amarelo, fase cerrado, sobre o crescimento e produção de laranjeira (Citrus sinennsis Osbeck cv. Baianinha). Viçosa, v.19. n.10, p.211-238, 1975.

PAIVA, A.Q. Dinâmica da água em uma topossequência de solos de tabuleiros do Estado da Bahia e sua implicação no crescimento da laranjeira, Viçosa, 1997. 74p (Dissertação de mestrado).

PETERSEN,G.W; CUNNINGHAM, R.L.; MATELSKI, R.P.; MOISTURE, R.L.; MATELSKI, R.P. Moisture Characteristics Of Pennyvanic Soil. I. Moisture Retention As Related To Texture. Soil Science Society of American Proceedings v.32, p.271-275, 1968.

RADAMBRASIL. Levantamento de recursos naturais: Salvador: Geologia, Geomorfologia, Pedologia, Vegetação, Uso potencial da terra. Rio de Janeiro, RJ: Ministério das Minas e Energia, 1981.620p.

REICHARDT, K. Capacidade de campo. Revista Brasileira de Ciência do Solo. v.12, p.211-216, 1988.

REICHARDT, K. Processos de transferência no sistema solo - planta atmosfera. $4{ }^{\text {a }}$ ed., Fundação Cargill, 1985. 445p. 
REUNIÃO TÉCNICA DE SOLOS COESOS DE TABULEIROS COSTEIROS. CruZ das Almas; Resumo Executivo. Cruz das Almas; UFBA; Escola de Agronomia, 1996. 12p.

RIBEIRO, L.P. Primeiras avaliações sobre a gênese dos solos coesos da Região de Cruz das Almas - BA. In: Table rounde surlorganization et dinamique interne de la coverture pedologique et son importance pour la morfogênese, Caen, 1991. Caen: CNRS, 1991. 35p.

RIBEIRO, L.P. Gênese. Primeiras avaliações sobre a gênese dos solos coesos da Região de Cruz das Almas-BA. Salvador, UFBA, (S.d.), 22p.

RIBEIRO, L.P. Horizontes coesos em Latossolos de tabuleiros. In: SEMANA DE GEOQUÍMICA DOS PAÍSES DE LÍNGUA PORTUGUESA, 2; Porto: Universidade do Porto: Faculdade de Ciências e Laboratório Mineralógica, 1993. p.496-500.

RIBEIRO, L.P. Primeiras avaliações sobre a gênese dos solos coesos da região de Cruz das Almas, BA, Salvador, UFBA, 1991. 33p.

RIVERS, E.D. SHIPP, R.F. Soil Water Retention to Particle Size. In: Selected Sands and Loamy Sands. Soil Science. Baltimore, v.126, p.94-100, 1978.

RUSSEL, E.J.; RUSSEL, R.W. Conditions and plant growth. 9. ed. London, Longmam \& Green, 1961. 770p.

SARAIVA, O.F. Relações da matéria orgânica com as características físicas e químicas de um Podzólico Vermelho Amarelo Câmbio distrófico, fase terraço, submetido a sistemas de cultivo. Viçosa, 1987. 175p. (Doutorado Universidade Federal de Viçosa).

SILVA, L.F. Zoneamento agroecológico do Nordeste: Diagnóstico do quadro natural e agro-sócioeconômico. Recife: EMBRAPA, CPATSA, 1993. 
SILVA, L.F. da. Alterações edáficas em solos de tabuleiros por influência do desmatamento, queima e sistemas de manejo. Revista Theobroma, Itabuna, v.11. n.1, p.5-9, 1981.

SILVA, L.F. da. Manejo dos recursos naturais dos trópicos e suas conseqüências, contradições e perspectivas de uso em agricultura sustentável. Agrotrópica. v.3, n.1, p.15-22. 1991.

SKIDMORE, E.L.; CARSTENSON, W.A.; BANBURY, E.E. Soil changes resulting from cropping. Soil Science of American Proceedings. Madison, v.39, n.4, p.964-967. 1975.

SOCIEDADE BRASILEIRA DE CIÊNCIA DO SOLO. Roteiro de excursão a Cruz das Almas. Salvador, 1981. 41p.

SOUZA, L.S. Uso e manejo dos solos coesos do tabuleiro costeiro. In: Reunião Técnica Sobre Solos Coesos Dos Tabuleiros Costeiros, Pesquisa e desenvolvimento para os tabuleiros costeiros,1996, Cruz das Almas, BA. Anais. Aracaju, SE: EMBRAPA/CPATC, 80p., p.36-75.

TAYLON, H.M.; GARDNER, H.R. Penetration of cotton seedling taaprots as influenced by bulk density, moisture content and stregth of soil. Soil Science. v.96, p.153-156. 1963.

TISDALL, J.M.; OADES, J.M. Organic matter and water - stable aggregates in soils. Journal of Soil Science, Oxford, v.33, n.2, p.141-163, 1982.

UFV - Universidade Federal de Viçosa. Caracterização de solos e avaliação dos principais sistemas de manejo dos Tabuleiros Costeiros do Baixo Rio Doce e da Região Norte do Estado do Espírito Santo e sua interpretação para o uso agrícola. Escola de Agronomia, UFV e CVRD, 1984. 58p.

van GENUTCHEN, M.Th. A closed form equation for predicting the hidraulic conductivity of unsaturated soil. Soil Science Society of America Journal, v.44, p.892-898, 1980. 
VIEIRA, M.J. Propriedades físicas do solo. In: Fundação Instituto Agronômico do Paraná. Plantio direto no Estado do Paraná. Londrina, IAPAR, p.19-32, 1981. (IAPAR. CIRCULAR, 23).

YOSHIDA, D. Efeitos de dois sistemas de cultivo em algumas propriedades físicas do solo. Científica, Jaboticabal, v.19, n.1, p.103-127, 1991. 
APÊNDICE 


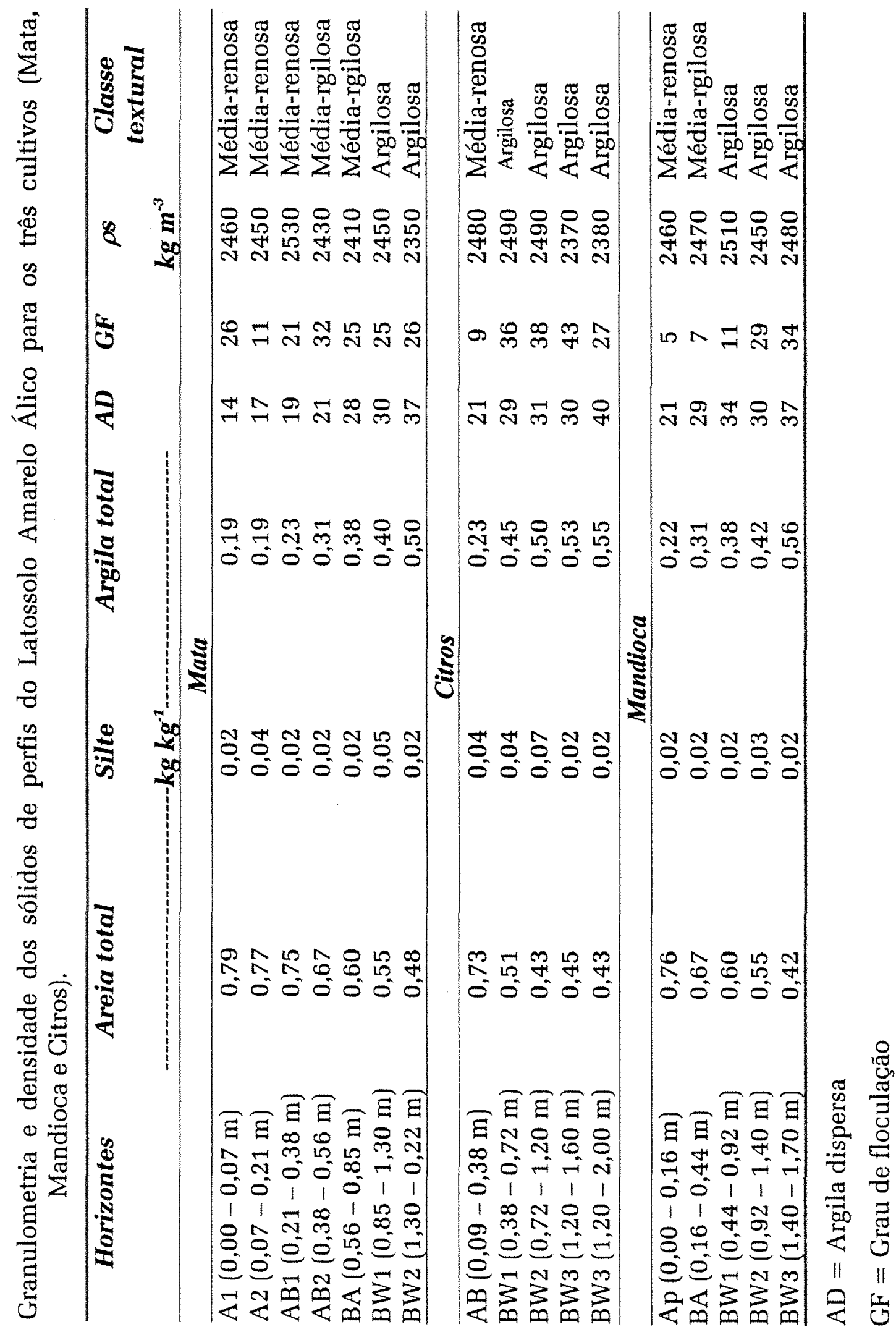




\section{CLASSIFICAÇÃO E MOROFOLOGIA DO SOLO ESTUDADO NOS TRÊS SISTEMAS DE CULTIVO (MATA, CITROS E MANDIOCA)}

\section{Classificação do solo, perfil da Mata.}

CLASSIFICAÇÃO : Latossolo amarelo álico podzólico a moderado; textura argilosa; fase floresta subperenifólia; relevo plano.

LOCALIZAÇÃO: Mata da Prefeitura de Cruz das Almas.

SITUAÇÃO E DECLIVE: Topo plano de Chapada.

COBERTURA VEGETAL SOBRE O PERFIL: Floresta subperenifólia.

LITOLOGIA E CRONOLOGIA: Formação Barreiras Terciários.

MATÉRIAL ORIGINÁRIO: Sedimentos argilo-arenosos.

PEDREGOSIDADE: Ausente.

ROCHOSIDADE: Ausente.

RELEVO LOCAL: Plano.

RELEVO REGIONAL: Plano.

EROSĀO: Não aparente.

DRENAGEM: Bem drenado.

VEGETAÇÃO PRIMÁRIA: Floresta subperenifólia.

USO ATUAL : Cobertura florestal primária.

DESCRITO E COLETADO: Melo Filho, H.F.R. \& Araújo Filho, J.O SNLCS/EMBRAPA.(Não publicado) 


\section{Descrição morfológica do solo, perfil da Mata}

0/ A 0-0,2 m ; constituído por folhas em decomposição.

$\mathrm{A}_{1}$ 0-0,7 m ; bruno (10 YR 5/3, seco ); bruno amarelado escuro (10 YR 4/4, seco triturado ), bruno acinzentado muito- escuro (10 Y R 3,5/2, úmido amassado); franco -argilo -arenoso; moderada média a grande granular e grãos simples; ligeiramente duro, friável, ligeiramente plástico e ligeiramente pegajoso; transição plana e clara.

$\mathrm{A}_{2}$ 7-0,21 m; bruno amarelado (10Y $\mathrm{R} 5 / 4$, seco e seco triturado ); bruno amarelado -escuro (10 YR 4/4, úmido e úmido amassado); franco argiloarenoso; fraca a moderada pequena e média granular; ligeiramente duro, friável, plástico e ligeiramente pegajoso; transição ondulada $(16-26 \mathrm{~cm})$ e clara. $\mathrm{AB}_{1}$ 0,21-0,38 m; bruno amarelado (10 YR 5/4, seco ) e bruno amareladoescuro (10 YR 4/4 úmido ); franco argilo- arenoso; fraca pequena e média blocos subangulares, friável, plástico e pegajoso, transição plana e difusa.

$\mathrm{AB}_{2}$ 0,38-0,56 m; bruno amarelado ( $10 \mathrm{YR} 5 / 4$, seco ) e bruno amareladoescuro (10 YR 4/4 úmido ) ; franco argilo- arenoso; fraca pequena e média blocos subangulares; friável, plástico e pegajoso, transição plana e difusa.

BA 0,56-0,85 m; bruno amarelada (10 YR 5/4, seco ) e bruno amarelado escuro (10 YR 4/4, úmido); argilo- arenoso; fraca pequena e média em blocos subangulares; friável, plástico e pegajoso; transição plana e gradual.

$\mathrm{BW}_{1}$ 0,85-0,130 m; bruno amarelado (10 YR 5/4, seco ) e bruno amarelado escuro ( 10 YR 4/4, úmido); argilo-arenoso; fraca pequena e média em blocos subangulares; friável, plástico e pegajoso; transição plana e difusa.

$\mathrm{BW}_{2}$ 0,130-0,220 $\mathrm{m}+$; bruno amarelado (10 YR 5/8, úmido); argila; fraca pequena e médias em blocos subangulares; friável, plástico e pegajoso.

RAÍZES: Muitas raízes finas e pouco médias no $A_{1}$, comuns finas e médias no $A_{2}$, poucas finas e médias no $B A$ 


\section{Observações:}

Poros comuns médios e poucos grandes e pequenos no $A_{1}$; poros comuns pequenos e médios e poucos grandes no $A_{2}$; poros comuns muito pequenos e pequenos, poucos médios, no $\mathrm{AB}_{1}, \mathrm{AB}_{2}$ e $\mathrm{BA}$; muitos poros muito pequenos e pequenos, e poucos médios $\mathrm{BW}_{1}$ e $\mathrm{BW}_{2}$.

Solo úmido a partir de $\mathrm{AB}_{1}$ 


\section{Classificação do solo, perfil do Citros.}

CLASSIFICAÇÃO- Latossolo amarelo distrófico A moderado textura argilosa fase transição floresta tropical subperenifólia/ subcaducifólia declive de 0 a 3 $\%$.

LOCALIZAÇÃO- Próximo à cerca, no experimento de leguminosa.

SITUAÇÃO, DECLIVE E COBERTURA VEGETAL SOBRE O PERFIL.-Trinceira em topo plano de chapada, com 0 a $2 \%$ de declividade e sob capim brachiária ALTITUDE-220 metros.

LITOLOGIA E CRONOLOGIA- sedimentos argilo- arenosos. Formação Barreiras. Terciários.

MATERIAL ORIGINÁRIO- Sedimentos argilo-arenosos.

PEDREGOSIDADE- Não pedregoso.

ROCHOSIDADE- Não rochoso

RELEVO LOCAL- Plano.

RELEVO REGIONAL -Plano.

EROSÃO - Laminar ligeira.

DRENAGEM- Bem drenado.

VEGETAÇĀO PRIMÁRIA- Transição floresta tropical subperenifólia/ subcaducifólia.

USO ATUAL- Cultura de laranja.

DESCRITO E COLETADO POR- Heraclio F. R. de Melo Filho e José A. Dantas. 


\section{Descrição morfológica do solo, perfil do Citros}

Ap-0-0,9 m, bruno- escuro (10 YR 3/3, úmido e bruno (10 YR 5/3, seco); franco argilo-arenoso; moderada pequena granular e fraca pequena blocos subangulares; ligeiramente duro, friável, ligeiramente plástico e ligeiramente pegajoso; transição plana e clara.

AB-0,9- 0,38 m, bruno- amarelado- escuro (10 YR 4/4, úmido) e brunoamarelado ( 10 YR 5/4 seco ); argila arenosa; fraca pequena e média blocos subangulares; ligeiramente duro a duro, friável, ligeiramente plástico e ligeiramente pegajoso; transição plana e gradual.

BW1- 0,38-0,72 m, bruno- amarelado (10 YR 5/8); argila; fraca pequena e média blocos subangulares; ligeiramente duro, muito friável, plástico e pegajoso, transição plana e difusa.

BW3- 0,12- 0,16 $\mathrm{m}+$, bruno- amarelado (10 YR 5/4 ); argila arenosa; fraca pequena e média blocos subangulares; ligeiramente duro, muito friável, plástico e pegajoso.

RAÍZES- Muitas raízes finas no Ap e comuns nos demais horizontes.

\section{Observação:}

Poros comuns pequenos e médios no Ap; muitos poros muito pequenos e pequenos no $A B$; e muitos poros muito pequenos e pequenos e comuns os médios no $\mathrm{BW}_{1}, \mathrm{BW}_{2}$ e $\mathrm{BW}_{3}$. 


\section{Classificação do solo, perfil da Mandioca.}

CLASSIFICAÇÃO : Latossolo amarelo álico, A moderado textura franco argiloarenosa fase transição floresta tropical subperenifólia/ subcaducifólia declive 0 a $3 \%$.

LOCALIZAÇĀO : Área de mandioca.

SITUAÇÃO E DECLIVE: Trincheira em topo plano de chapada, com $2 \%$ de declividade, sob cultura de mandioca.

ALTITUDE: 220 metros.

LITOLOGIA E CRONOLOGIA: Sedimentos argilo-arenosos. Formação Barreiras. Terciário.

MATÉRIAL ORIGINÁRIO: Sedimentos argilo-arenosos.

PEDREGOSIDADE: Não pedregoso.

ROCHOSIDADE: Não rochoso.

RELEVO LOCAL: Plano.

EROSÃO: Laminar ligeira.

DRENAGEM: Bem drenado.

VEGETAÇĀO PRIMÁRIA: Transição floresta tropical subperenifólia/ subcaducifólia.

USO ATUAL : Experimento de mandioca.

DESCRITO E COLETADO: Heraclio F. R. de Melo Filho e José A Dantas. 


\section{Descrição morfológica do solo, perfil da Mandioca}

Ap- 0-0,16 m, bruno- escuro (10 YR 3/3, úmido ) e bruno (10YR 4/3, seco); franco argilo-arenoso; moderada pequena e média granular e fraca pequena blocos subangulares; ligeiramente duro, friável ,ligeiramente plástico e ligeiramente pegajoso; transição plana e clara.

BA- 0,16-0,44 m, bruno (10YR 5/3 e úmido) e bruno- amarelado (10 YR 5/4, seco ); franco argilo- arenoso; fraca pequena e média blocos subangulares; ligeiramente duro, friável, plástico e ligeiramente pegajoso; transição plana e gradual.

$\mathrm{BW}_{1}-$ 0,44-0,92 m, bruno- amarelado (10 YR 5/4, úmido e bruno - amarelado (10 YR 5/6, seco ); argila arenosa; fraca pequena e média blocos subangulares; ligeiramente duro a duro, friável, plástico e pegajoso; transição plana e difusa. $\mathrm{BW}_{2}-0,92-0,140 \mathrm{~m}$, bruno- amarelado (10 YR 5/4, úmido ) e bruno amarelado (10 YR 5/6, seco ) ; argila arenosa; fraca pequena e média blocos subangulares; ligeiramente duro, friável, plástico e pegajoso; transição plana e difusa $\mathrm{BW}_{3}-$ 0,140-0,170 $\mathrm{m}+$, bruno amarelado (10 YR 5/6, úmido ) e amarelobrunado (10 YR 6/6, seco ) ; argila; fraca pequena e média blocos subangulares; ligeiramente duro, friável, plástico e pegajoso.

RAÍZES- Comuns as raízes finas no Ap e BA e raras nos demais Horizontes. 